NBER WORKING PAPER SERIES

LABOR SUPPLY HETEROGENEITY AND MACROECONOMIC CO-MOVEMENT

\author{
Stefano Eusepi \\ Bruce Preston \\ Working Paper 15561 \\ http://www.nber.org/papers/w15561
}

NATIONAL BUREAU OF ECONOMIC RESEARCH

1050 Massachusetts Avenue

Cambridge, MA 02138

December 2009

The authors thank Gianluca Violante for his help with the Consumer Expenditure Survey data, Stefania Albanesi, Roc Armenter, Carlos Carvalho and Aysegul Sahin for extensive comments and discussions. The Authors also thank seminar participants at Columbia University, Federal Reserve Bank of Atlanta, La Trobe University, Midwest Macroeconomics Meeting 2009, SED 2009, the Southern Workshop in Macroeconomics 2009, the European Economic Association and Econometric Society European Meeting 2009, The University of Adelaide, University of Auckland, University of New South Wales and The University of Melbourne. The views expressed in the paper are those of the authors and are not necessarily reflective of views at the Federal Reserve Bank of New York, the Federal Reserve System, or the National Bureau of Economic Research. The usual caveat applies.

NBER working papers are circulated for discussion and comment purposes. They have not been peerreviewed or been subject to the review by the NBER Board of Directors that accompanies official NBER publications.

(C) 2009 by Stefano Eusepi and Bruce Preston. All rights reserved. Short sections of text, not to exceed two paragraphs, may be quoted without explicit permission provided that full credit, including $\odot$ notice, is given to the source. 
Labor Supply Heterogeneity and Macroeconomic Co-movement

Stefano Eusepi and Bruce Preston

NBER Working Paper No. 15561

December 2009

JEL No. E13,E24,E32

\begin{abstract}
$\underline{\text { ABSTRACT }}$
Standard real-business-cycle models must rely on total factor productivity (TFP) shocks to explain the observed co-movement between consumption, investment and hours worked. This paper shows that a neoclassical model consistent with observed heterogeneity in labor supply and consumption, can generate co-movement in absence of TFP shocks. Intertemporal substitution of goods and leisure induces co-movement over the business cycle through heterogeneity in consumption behavior of employed and unemployed workers. The result is due to two model features that are introduced to capture important characteristics of US labor market data. First, individual consumption is affected by the number of hours worked with employed consuming more on average than unemployed. Second, changes in the employment rate, a central explanator of total hours variation, then affects aggregate consumption. Demand shocks --- such as shifts in the marginal efficiency of investment, government spending shocks and news shocks --- are shown to generate economic fluctuations consistent with observed business cycles.
\end{abstract}

\title{
Stefano Eusepi
}

Macroeconomic and Monetary Studies Function

Federal Reserve Bank of New York

33 Libery street

New York, NY 10045-0001

stefano.eusepi@ny.frb.org

Bruce Preston

Department of Economics

Columbia University

420 West 118th Street

New York, NY 10027

and NBER

bp2121@columbia.edu 


\section{Introduction}

Standard neoclassical business-cycle models of the kind proposed by Kydland and Prescott (1982) must rely on fluctuations in total factor productivity (TFP) to explain the observed co-movement between consumption, investment and hours worked — see Barro and King (1984). Intertemporal substitution of goods and leisure is the central determinant of equilibrium business cycles. Benchmark assumptions on preferences and technology, and constant TFP, predict that any change in consumption induces opposite movements in hours worked and investment. This "co-movement problem" has received much attention in the businesscycle literature interested in non-TFP-based explanations of fluctuations, such as variations in the marginal efficiency of investment due to financial frictions, or shifts in expectations generated by news about the future. ${ }^{1}$ For example, the former induce substitution between investment and current consumption and leisure. And positive 'news' shocks about future productivity induce strong wealth effects, increasing consumption and leisure at the expense of investment. The co-movement problem is also relevant to policy debate on the size of the fiscal multiplier, as negative co-movement following a fiscal expansion implies a multiplier which is less than one.

This paper shows that a model consistent with two empirical regularities in U.S. labor market data can generate co-movement in absence of TFP shocks. First, employed consume more than the non-employed and, second, variations in employment are the primary determinant of variations in total hours worked. These characteristics are captured by the following model assumptions. As predicted by theories of time allocation - for example Becker (1965) — individual consumption is affected by the number of hours worked: the employed consume more than the non-employed in compensation for supplying labor. In addition, the extensive margin of labor supply is modeled as costly labor market participation. Intertemporal substitution of goods and leisure then induces co-movement over the business cycle through a composition effect engendered by heterogeneity in the consumption behavior of employed and non-employed workers.

A widely adopted class of preferences is used, which are separable across time, but nonseparable over consumption and leisure. Preferences are restricted to imply: i) constant

\footnotetext{
${ }^{1}$ As noted by Campbell (1994), the standard RBC model with TFP shocks also fails to deliver comovement if the shock is more persistent than a random walk.
} 
hours worked on the balanced-growth path; ii) a constant consumption intertemporal elasticity of substitution; iii) a constant Frisch elasticity of labor supply on both the intensive and extensive margins; and iv) that consumption and hours are complements. This preference specification implies that, despite the assumption of full insurance, employed agents consume more than non-employed agents. It can be interpreted as a reduced-form representation of a more complicated decision problem with home production. Increases in labor supply increase resources devoted to market consumption. Preferences of this kind have been employed to resolve various puzzles in the consumption literature; to amplify technology shocks; and to improve empirical correspondence of model predicted movements in the marginal product of labor and the marginal rate of substitution between consumption and leisure. $^{2}$

The adopted preferences have the additional advantage of being, in principle, consistent with evidence on the magnitude of wealth effects on labor supply provided by Kimball and Shapiro (2008). This contrasts with preferences proposed by Greenwood, Hercowitz, and Huffman (1988), which, by eliminating such wealth effects by assumption, have been successfully employed to resolve questions of co-movement in classical theory. ${ }^{3}$ The intent here is to calibrate the model to observable characteristics of the labor market and only then assess properties relating to co-movement.

Two restrictions on the analysis enhance the generality of our findings. First, the analysis remains strictly within the purview of neoclassical theory. While not denying that various market inefficiencies and frictions may be relevant for co-movement, such approaches often rely either on the absence of optimal policy and at times quite specific choices of policy; the introduction of parameters which, unrestricted, can be varied to deliver desired properties; or on the magnitudes of inefficiencies which are not directly observable. ${ }^{4}$ Determining a framework that generates co-movement without such additional assumptions has appeal, understanding that richer models incorporating a neoclassical core will likely inherit these

\footnotetext{
${ }^{2}$ See, respectively, Basu and Kimball (2000), King and Rebelo (1999) and Hall (2009). Other recent papers employing non-separable preferences include Baxter and Jermann (1999), Dotsey and King (2006), Shimer (2009) and Trabandt and Uhlig (2006).

${ }^{3}$ Jaimovich and Rebelo (2008) propose this class preferences to resolve the comovement problem arising from news shocks. Other examples include Monacelli and Perotti (2008) and Chen and Song (2007).

${ }^{4}$ See, for example, Chen and Song (2007), Christiano, Ilut, Motto, and Rostagno (2007) and Den Haan and Kaltenbrunner (2007).
} 
properties. ${ }^{5}$ Second, our approach abjures reliance on movements in current total factor productivity in contrast to other recent papers that adopt economy-wide increasing returns in production. ${ }^{6}$ This renders co-movement difficult for the same reason that variations in TFP are centrally located in classical theory.

In a special case of our model, analytical results are provided on the parametric requirements for co-movement. Co-movement is shown to hinge on the magnitude of the consumption differential between the employed and unemployed and the relative importance of the intensive and extensive margin of labor supply. Enriching the model with variable capacity utilization and habit formation are, either individually or in combination, shown to weaken the requirements for co-movement; but are by no means necessary for our central results. In all cases, heterogeneity together with hours variation on the extensive margin engenders comovement. Both are necessary. Bilbiie (2009) shows that non-separability in consumption and leisure in a representative agent model cannot generate co-movement without violating concavity of the utility function or the assumption of normality of consumption. And models with heterogeneous employment decisions and full insurance, such as Rogerson (1988), imply consumption is equalized across agents so that variations in employment do not produce composition effects on aggregate consumption.

Armed with these insights, properties of the general model are evaluated numerically. The model is calibrated to U.S. data. Matching certain model characteristics with corresponding data characteristics requires exploration of micro data. First, the steady-state ratio of unemployed-to-employed consumption - a key quantity in our model — is inferred from Consumer Expenditure Survey data on household consumption at different levels of labor supply. Second, the consumption intertemporal elasticity of substitution, chosen to deliver model consistency with the value of non-work activities suggested by Hall (2006) and Shimer (2005), is in line with empirical evidence and the range of values frequently used in macroeconomics. The calibration ensures preferences satisfy concavity of the utility function and normality of consumption and leisure. Third, the employment response to the

\footnotetext{
${ }^{5}$ More richly specified models with separable preferences, that include nominal and real frictions, can mitigate but not fully resolve these shortcomings - see Smets and Wouters (2007) and Justiniano, Primiceri, and Tambalotti (2008).

${ }^{6}$ See, for example, Comin, Gertler, and Santacreu (2009) and Li and Mehkari (2009). Again, the plausibility of such mechanisms is not denied. However, it is not obvious that demand-side shocks should only be source of business-cycle co-movement to the extent that they generate sufficiently large shifts in TFP.
} 
wage rate is determined to be consistent with the observed contribution of intensive and extensive margins to total variation in hours worked.

Model dynamics are explored conditional on demand shocks, such as shifts in the marginal efficiency of investment, government spending shocks and news shocks about future TFP. The model generates co-movement conditional on each of these disturbances and business-cycle properties that are broadly consistent with aggregate data. It should be emphasized that while this paper proposes a model that can in principle generate business-cycle fluctuations driven by non-TFP shocks, it is not about the quantitative importance of such shocks. This is left to future research.

\section{The co-movement problem}

For a given level of TFP, real-business-cycle theory fails to produce co-movement between hours and consumption. Consider the following equilibrium labor market condition, derived under standard assumptions about preferences and technology,

$$
\left[\phi_{N}+(1-\alpha) \alpha\right] \ln N_{t}=(1-\alpha) \ln T F P_{t}-\ln C_{t}+(1-\alpha) \alpha \ln K_{t}
$$

where $\phi_{N}>0$ is the inverse Frisch elasticity of labor supply, $0<\alpha<1$ is the capital share in a Cobb-Douglas production function, and $N_{t}, C_{t}$ and $K_{t}$ are hours, consumption and capital. Capital is predetermined.

Without total factor productivity shocks, which shift the demand for labor, hours and consumption must be negatively correlated. On the one hand, any shock inducing strong substitution effects leads to a reduction in consumption and leisure to increase investment. On the other hand, any shock generating positive wealth effects increases consumption and leisure at the expense of investment. The real-business-cycle model predicts labor and consumption can move together, if, and only if, labor productivity co-moves more than proportionally to consumption. Joint expansion of total hours, consumption and investment requires a sufficiently strong increase in aggregate total factor productivity. The assumption of increasing returns at the aggregate level can solve the co-movement problem by having TFP endogenously increase to a sufficient degree. This is not the route taken in this paper. The production side of the economy described below displays constant returns to scale. 


\section{The model}

In this section we describe the main features of our model.

Households. Each household is composed of a continuum of members of unit measure. The household decides whether a given member participates in the labor market and, if so, how many hours to work. Participating in the labor market entails a cost. There is perfect risk sharing within the household. The household's problem is to maximize

$$
E_{t} \sum_{T=t}^{\infty} \beta^{T-t}\left[e_{T} \frac{\left(C_{T}^{e}-b C_{T-1}\right)^{1-\sigma} \nu\left(n_{T}\right)}{1-\sigma}+\left(1-e_{T}\right) \frac{\left(C_{T}^{u}-b C_{T-1}\right)^{1-\sigma} \nu(0)}{1-\sigma}-X_{T}^{1-\sigma} \Phi\left(e_{T}\right)\right]
$$

where $C_{t}^{e}$ is the consumption of the employed; $C_{t}^{u}$ consumption of the unemployed; $e_{t}$ the fraction of household members participating in the labor market; $0<\beta<1$ the discount factor; and $\sigma>1$. The latter restriction implies that consumption and leisure are substitutes, as predicted by theories of time allocation — see Becker (1965).

The function $\nu(\cdot)$ satisfies $\nu^{\prime}(\cdot), \nu^{\prime \prime}(\cdot)>0$. Restrictions on $\nu(\cdot)$ discussed in section 5 ensure that, given $\sigma>1$ : i) individual labor supply has a constant Frisch elasticity; ii) utility is concave; and iii) consumption and leisure are normal goods. This utility function is consistent with a balanced growth path — see Basu and Kimball (2000). Following Abel (1990), household utility depends on lagged aggregate consumption, defined as

$$
C_{t}=e_{t} C_{t}^{e}+\left(1-e_{t}\right) C_{t}^{u}
$$

as in the "catching up with the Jonses" version of habit formation.

The function $\Phi\left(e_{t}\right)$ denotes a time-invariant cost of participation, which we keep distinct from the disutility incurred from hours worked - see, for example, Cho and Cooley (1994). It has the properties

$$
\Phi(\bar{e})>0, \Phi_{e}(\bar{e})>0, \Phi_{e e}(\bar{e})>0
$$

where $\bar{e}$ denotes the steady-state participation rate. For a balanced growth path to exist, the cost function is discounted by the level of labor augmenting technical progress $X_{t}$, where $\ln \left(X_{t}\right)-\ln \left(X_{t-1}\right)=\ln (\bar{\gamma})$ and $\bar{\gamma}>0$. Whether technology has a stochastic or deterministic trend or is a stationary process is unimportant for the question of co-movement.

Maximization occurs subject to the budget constraint

$$
C_{t}+q_{t}^{-1} I_{t}=R_{t}^{K} U_{t} K_{t}+W_{t} N_{t}
$$


and the capital accumulation equation

$$
K_{t+1}=I_{t}\left[1-\phi\left(\frac{I_{t}}{I_{t-1}}\right)\right]+\left[1-\delta\left(U_{t}\right)\right] K_{t}
$$

Labor market participants supply $n_{t}$ hours of work at the competitive wage $W_{t}$. The total numbers of hours worked is $N_{t}=e_{t} n_{t}$. The household supplies capital services to firms at the competitive rental rate $R_{t}^{K}$. Capital services depend on the available stock of capital $K_{t}$ and on the degree of utilization $U_{t}$. Consumption goods can be transformed into investment goods at the price $q_{t}^{-1}$, which is an exogenously given stochastic process.

Investment adjustment costs depend on the function $\phi(\cdot)$ which satisfies

$$
\phi(1)=\phi^{\prime}(1)=0 \text { and } \phi^{\prime \prime}(1) \geq 0
$$

Finally, the capital depreciation depends on the degree of capacity utilization according to the function

$$
\delta(\bar{U})=\delta, \delta^{\prime}(\bar{U})>0 \text { and } \delta^{\prime \prime}(\bar{U})>0 .
$$

Risk sharing. The first-order conditions with respect to consumption of the employed and unemployed are

$$
\begin{aligned}
& \left(C_{t}^{e}-b C_{t-1}\right)^{-\sigma} \nu\left(n_{t}\right)=\Lambda_{t} \\
& \left(C_{t}^{u}-b C_{t-1}\right)^{-\sigma} \nu(0)=\Lambda_{t},
\end{aligned}
$$

where $\Lambda_{t}$ is the Lagrange multiplier on the budget constraint. Together they imply the risk-sharing condition

$$
\frac{C_{t}^{e}-b C_{t-1}}{C_{t}^{u}-b C_{t-1}}=\left[\frac{\nu\left(n_{t}\right)}{\nu(0)}\right]^{\frac{1}{\sigma}} .
$$

Employed household members enjoy greater consumption as compensation for disutility of work effort.

Labor supply. The first-order condition with respect to participation provides

$$
\frac{1}{1-\sigma}\left[\left(C_{t}^{u}\right)^{1-\sigma} \nu(0)-\left(C_{t}^{e}\right)^{1-\sigma} \nu\left(n_{t}\right)\right]=\Lambda_{t}\left[W_{t} n_{t}-C_{t}^{e}+C_{t}^{u}\right]-X_{t}^{1-\sigma} \Phi_{e}\left(e_{t}\right)
$$

which, rearranging, becomes

$$
\frac{\sigma}{\sigma-1}\left(C_{t}^{e}-C_{t}^{u}\right)=W_{t} n_{t}-\frac{\Phi_{e}\left(e_{t}\right)}{X_{t}^{\sigma-1} \Lambda_{t}} .
$$


The first-order condition with respect to hours gives

$$
\frac{\left(C_{t}^{e}-b C_{t-1}\right) \nu^{\prime}\left(n_{t}\right)}{\sigma-1}=\nu\left(n_{t}\right) W_{t} .
$$

Supply of capital services. The capital Euler equation is

$$
E_{t}\left\{\frac{\Lambda_{t+1}}{\Xi_{t}}\left(R_{t+1}^{K} U_{t+1}\right)+\frac{\Xi_{t+1}}{\Xi_{t}}\left[1-\delta\left(U_{t+1}\right)\right]\right\}=\beta^{-1}
$$

where $\Xi_{t}$ the the multiplier associated to the capital accumulation equation. Investment dynamics obey

$$
\frac{\Lambda_{t}}{q_{t}}=\Xi_{t}\left[1-\phi\left(\frac{I_{t}}{I_{t-1}}\right)-\frac{I_{t}}{I_{t-1}} \phi^{\prime}\left(\frac{I_{t}}{I_{t-1}}\right)\right]+\beta E_{t}\left[\Xi_{t+1}\left(\frac{I_{t+1}}{I_{t}}\right)^{2} \phi^{\prime}\left(\frac{I_{t+1}}{I_{t}}\right)\right] .
$$

Finally, capacity utilization is determined by

$$
\Lambda_{t} R_{t}^{K}=\Xi_{t} \delta^{\prime}\left(U_{t}\right)
$$

Firms. Output is produced by perfectly competitive firms with the Cobb Douglas production function

$$
Y_{t}=A_{t}\left(U_{t} K_{t}\right)^{\alpha}\left(X_{t} N_{t}\right)^{1-\alpha} .
$$

where $A_{t}$ is a stationary TFP shock, which is described in section 6.2. Firms' demand for labor and capital services is then

$$
R_{t}^{K}=\alpha \frac{Y_{t}}{U_{t} K_{t}}
$$

and

$$
W_{t}=(1-\alpha) \frac{Y_{t}}{N_{t}} .
$$

This completes the description of the model.

\section{Non-separability, participation and co-movement}

\subsection{Extensive margin only}

To provide intuition for the co-movement result, consider a special case of the model with no investment adjustment costs, no habit formation, no capacity utilization and no intensive margin. Assume that there is a fixed cost of participating so that $\Phi_{e}(\bar{e}) \rightarrow 0$. These 
assumptions admit analytical results. Details of the log-linearized model are described in the appendix.

Investment-specific technology shocks. Following Beaudry and Portier (2007), the model's intratemporal conditions are exploited to derive parametric restrictions required for co-movement between consumption, hours and investment. They are as follows. The participation decision requires

$$
\left(C_{t}^{e}-C_{t}^{u}\right)=\frac{(\sigma-1)}{\sigma} W_{t} \bar{n}
$$

where employed members of the household work a fixed number of hours $\bar{n}$. The first-order conditions for consumption allocation imply

$$
\frac{C_{t}^{e}}{C_{t}^{u}}=\left[\frac{\nu(\bar{n})}{\nu(0)}\right]^{\frac{1}{\sigma}}
$$

which states that consumption of the employed and unemployed move proportionally. Aggregate consumption and the real wage are defined as in (1) and (15), while the aggregate resource constraint is

$$
C_{t}+q_{t}^{-1} I_{t}=Y_{t}
$$

Log-linearizing these intratemporal conditions and rearranging using steady-state restrictions yields the constant-consumption aggregate labor supply condition

$$
\hat{C}_{t}=\hat{W}_{t}+\frac{(1-\omega)}{1+\left(\bar{e}^{-1}-1\right) \omega} \hat{N}_{t}
$$

where $N_{t}=\bar{n} e_{t}$ and $\omega=\bar{C}^{u} / \bar{C}^{e}$ is the steady-state ratio of unemployed-to-employed consumption. When $\omega=1$, equivalently ${ }^{7} \sigma=1$, preferences are separable in consumption and leisure. The consumption of employed and unemployed are then equal and the model implies a perfectly elastic labor supply, as in Hansen (1985) and Rogerson (1988). With $0<\omega<1$, employed members of the household consume more than the unemployed. This induces a positive relationship between aggregate consumption and total hours supplied to the market, for a given real wage.

Since capital is predetermined in the current period, (15) implies a negative relation between the real wage and the number of hours worked. In log-linear terms, and ignoring terms in the capital stock,

$$
\hat{W}_{t}=-\alpha \hat{N}_{t}
$$

\footnotetext{
${ }^{7}$ The relationaship between $\sigma$ and $\omega$ is shown formally in the appendix.
} 
Substituting this expression into (18) yields the relation

$$
\hat{C}_{t}=m_{\omega} \hat{N}_{t}
$$

between total hours and aggregate consumption, where

$$
m_{\omega}=\frac{(1-\omega)}{1+\left(\bar{e}^{-1}-1\right) \omega}-\alpha .
$$

The constant $m_{\omega}$ comprises two terms. The first is positive, indicating that an increase in hours worked increases aggregate consumption because the fraction of employed rises, and the employed consume more in equilibrium. This is a composition effect arising from consumption heterogeneity to which discussion will return. The second term is negative, reflecting that decreasing returns to the labor input imply increases in hours decrease the real wage, with concomitant declines in aggregate consumption. Sufficiently low values of $\omega$ guarantee positive co-movement between consumption and total hours worked.

Concerning the relation between investment and hours worked, combining the resource constraint, the production function and (19) yields

$$
\frac{\bar{I}}{\bar{Y}}\left(\hat{I}_{t}-\hat{q}_{t}\right)=\left(1-\alpha-\frac{\bar{C}}{\bar{Y}} m_{\omega}\right) \hat{N}_{t}
$$

where $\bar{I}, \bar{C}$ and $\bar{Y}$ are the steady-state values of investment, consumption and output. The coefficient on employment is positive and increasing in $\omega .^{8}$ Exogenous variation in the relative price of investment, $\hat{q}_{t}$, strengthens co-movement between hours and investment in the sense that falls in the relative price of investment are associated with rising investment and hours. The following proposition summarizes the result.

Proposition 1 For a given $\bar{e} \in(0,1)$ and $\alpha \in(0,1)$, there exists an $\omega^{*}$ such that for $0<$ $\omega<\omega^{*}$ the economy displays positive co-movement between aggregate hours, consumption and investment.

Remark 2 Perfectly elastic labor supply does not imply co-movement. Consumption heterogeneity from the non-separability of leisure and consumption is central to the result.

\footnotetext{
${ }^{8}$ Note that for $\omega \rightarrow 0$,$$
\frac{C}{Y}\left(\frac{1-\omega}{1+\left(\bar{e}^{-1}-1\right) \omega}-\alpha\right) \rightarrow \frac{C}{Y}(1-\alpha)<(1-\alpha)
$$ 
News shocks. Discussed later in detail, news shocks are modeled as signals about future total factor productivity. Conditions (19) and (20) also govern co-movement in this case. However, the nature of co-movement is fundamentally different: wealth effects dominate substitution effects so that consumption, investment and hours fall on receipt of positive news about the state of future technology. Positive wealth effects lead to a fall in employment and therefore aggregate consumption, even though individual consumption of the employed and unemployed rise. Market participants need not work and invest today to capture the benefits of higher TFP tomorrow. As such, the news shock produces only an increase in permanent income. Investment adjustment costs induce substitution effects which increase employment and investment in the current period, generating the "right" co-movement.

Spending shocks. In the sequel we also consider the effect of a spending shock, arising, for example, from government activities. Consider an exogenous component of aggregate demand $G_{t}$ that is for simplicity zero in steady state. The resource constraint requires

$$
\hat{G}_{t}=\hat{Y}_{t}-\frac{I}{Y} \hat{I}_{t}-\frac{C}{Y} \hat{C}_{t}
$$

Assuming lump-sum taxation and a balanced budget, the introduction of a disturbance to the resource constraint only affects relation (20). It becomes

$$
\frac{I}{Y}\left(\hat{I}_{t}-\hat{q}_{t}\right)=\left(1-\alpha-\frac{C}{Y} m_{\omega}\right) \hat{N}_{t}-\hat{G}_{t} .
$$

For $\omega<\omega^{*}$ consumption and hours are positively related but investment might increase or not, depending on model parameters, since increases in government spending crowd out investment — making co-movement less likely.

\subsection{Some Generalizations}

Two extensions permit analytical results: the inclusion of capacity utilization and habit formation. Both additions assist generating co-movement.

Capacity utilization. Capacity utilization increases the ability of the model to generate co-movement by mitigating the effects of diminishing returns to labor input. Log-linearizing (12) and (14) and combining the two expressions gives

$$
\hat{U}_{t}=\frac{1-\alpha}{\epsilon_{\delta}+1-\alpha} \hat{N}_{t}
$$


where $\epsilon_{\delta} \equiv \delta^{\prime \prime}(\bar{U}) \bar{U} / \delta^{\prime}(\bar{U})>0$. The wage then can be expressed as

$$
\hat{W}_{t}=\left(\frac{1-\alpha}{\epsilon_{\delta}+1-\alpha}-1\right) \alpha \hat{N}_{t}
$$

which, substituted into (18), yields $\hat{C}_{t}=\bar{m}_{\omega} \hat{N}_{t}$ where

$$
\bar{m}_{\omega}=\frac{(1-\omega)}{1+\left(\bar{e}^{-1}-1\right) \omega}-\left(1-\frac{1-\alpha}{\epsilon_{\delta}+1-\alpha}\right) \alpha .
$$

It is evident that $\bar{m}_{\omega}>m_{\omega}$. The relation between investment and hours becomes

$$
\frac{\bar{I}}{\bar{Y}}\left(\hat{I}_{t}-\hat{q}_{t}\right)=\left[(1-\alpha)-\frac{\bar{C}}{\bar{Y}} \bar{m}_{\omega}\right] \hat{N}_{t}
$$

In this case, provided $(1-\alpha)>\bar{C} / \bar{Y}$, co-movement between total hours and investment is guaranteed for every value of $\epsilon_{\delta}$.

These expressions nest the results for the model without variable capacity utilization. Specifically, when $\epsilon_{\delta} \rightarrow \infty$, so that depreciation costs become infinitely elastic with respect to utilization rates. Note also that as $\epsilon_{\delta} \rightarrow 0$, depreciation costs become completely inelastic and co-movement is guaranteed for every $\omega<1$. Variations in utilization rates are used to fully off-set negative co-movement induced by diminishing marginal returns.

Habit formation. Consider now the simple model where only habit formation is added. Using the first-order condition for employment, individual consumption of employed and unemployed, and the definition of aggregate consumption, provides

$$
\hat{C}_{t}=\tilde{m}_{\omega} \hat{N}_{t}
$$

where

$$
\tilde{m}_{\omega}=\frac{(1-\omega)}{1+\left(\bar{e}^{-1}-1\right) \omega}-(1-b) \alpha .
$$

As in the case of capacity utilization, habit formation per se does not generate positive co-movement. Coupled with non-separable preferences and the extensive margin it facilitates co-movement by making some part of current consumption predetermined. This weakens the effect of variations in the real wage on aggregate consumption. Similarly, the relation between investment and hours becomes ${ }^{9}$

$$
\frac{I}{Y}\left(\hat{I}_{t}-\hat{q}_{t}\right)=\left(1-\alpha-\frac{C}{Y} \tilde{m}_{\omega}\right) \hat{N}_{t}
$$

The discussion above can be summarized by the following proposition.

\footnotetext{
${ }^{9}$ Again, a sufficient restriction for positive comovement between hours and investment is $\frac{\bar{C}}{\bar{Y}}<1-\alpha$. In a plausible calibration values of $\omega>0.5$ imply positive comovemnt even if $\frac{\bar{C}}{\bar{Y}}>1-\alpha$.
} 
Proposition 3 Consider the model with habit formation and capacity utilization:

1) for $\omega=1, m_{\omega}<0$ for independently of $\epsilon_{\delta}$ and $b$;

2) for $\omega<1, \frac{\partial \omega^{*}}{\partial \epsilon_{\delta}}>0$ and $\frac{\partial \omega^{*}}{\partial b}>0$,

where $\omega^{*}$ is such that for $0<\omega<\omega^{*}$ the economy displays positive co-movement between aggregate hours, consumption and investment.

To give an idea of the role of $\omega$ in a model with both capacity utilization and habit formation, suppose $\alpha=0.3, \bar{e}=0.7, \epsilon_{\delta}=0.15$ and $b=0.5$. Then positive co-movement obtains for values of $\omega$ as high as 0.96. This suggests that co-movement can be obtained for reasonable values of $\omega$. This is discussed further in the calibration section.

\subsection{Intensive margin}

This section delineates the joint implications of non-separable preferences and the intensive margin for co-movement. Thus far it has been assumed that variations in total hours are driven only by changes in employment. However, in U.S. data, the intensive margin plays a non-negligible role in explaining movement in hours worked. Such variation can generate undesirable predictions in models with non-separable preferences. These predictions are not a feature of our model.

A consequence of introducing the choice of how many hours to work is that workers' utility is affected by both movement in hours and consumption. Non-separable preferences in consumption and leisure have been proposed before in business-cycle models. King and Rebelo (1999) and Hall (2008) demonstrate non-separable preferences increase co-movement of consumption with output and hours, when the main driving force of the business cycle are total factor productivity shocks. ${ }^{10}$ More closely related to this paper, non-separable preferences have been proposed to explain business cycles in absence of productivity shocks. Bennett and Farmer (2000) show that non-separable preferences can generate indeterminate equilibria and thus expectations-driven business cycles, a form of animal spirits. But the chosen preference specification violates concavity — see Hintermaier (2003). Linnemann (2006) considers government spending shocks and shows that non-separable preferences can generate co-movement between government expenditures and consumption. But, as shown in Bilbiie (2008), this implies that consumption is an inferior good. That paper shows

\footnotetext{
${ }^{10}$ King and Rebelo (1999) discuss an extension of the Rogerson (1988) model to non-separable preferences. They consider the extensive margin only. Hall (2008) includes non-separable preferences in a model with frictional unemployment and real wage rigidities.
} 
for a general class of non-separable preferences, which satisfy concavity and normality of both consumption and leisure, co-movement between consumption and hours cannot be obtained in a representative agent model. The appendix demonstrates that the class of preferences considered in this paper satisfies both assumptions. The result is summarized by the following proposition, employing the definitions, $s_{e} \equiv \bar{C}^{e} \bar{e} / \bar{C}$, the share of employed consumption in aggregate consumption, and $\zeta$ the marginal cost of participation as a fraction of the aggregate wage bill discussed in detail in the sequel.

Proposition 4 Let $\phi_{N}$ be the Frisch elasticity of the supply of hours worked. Assume $\omega s_{e}-b \gamma^{-1} \bar{e}>0$ and let $\bar{\phi}_{N}=\frac{1-\omega}{1-\zeta}\left\{1-\bar{e} b \bar{\gamma}^{-1}\left[1+\left(\bar{e}^{-1}-1\right) \omega\right]\right\}^{-1}$. For $\phi_{N}>\bar{\phi}_{N}$

1) the utility function is concave;

2) consumption and leisure are normal goods.

Because of the restrictions imposed by concavity and normality, the intensive margin has important implications for co-movement. While analytical results are not available, some implications can be inferred from first-order conditions. Consider the full model specified in section 2. The employed supply labor according to

$$
\phi_{N} \hat{n}_{t}=\hat{W}_{t}+\sigma^{-1} \hat{\lambda}_{t}
$$

Combining (21) with the log-linearized expression for (4) gives a constant-consumption individual labor supply

$$
\left(\phi_{N}-\bar{\phi}_{N}\right) \hat{n}_{t}=\hat{W}_{t}+\left(s_{e}-\bar{e} b \bar{\gamma}^{-1}\right)^{-1}\left[-s_{e} \hat{C}_{t}^{e}+b \bar{e} \bar{\gamma}^{-1}\left(\hat{C}_{t-1}-\hat{\gamma}_{t}\right)\right]
$$

As shown in proposition 4, normality of preferences implies a negative relation between individual hours and individual consumption absent technology shocks. ${ }^{11}$ Introducing the intensive margin necessarily weakens co-movement. However, the non-separability of preferences implies a smaller effect on consumption from a change in hours worked than in the standard case of separable preferences where $\bar{\phi}_{N}=0$.

This property of non-separable preferences reveals the extensive margin as crucial in obtaining co-movement. Aggregate consumption satisfies

$$
\hat{C}_{t}=s_{e} \hat{C}_{t}^{e}+\left(1-s^{e}\right) \hat{C}_{t}^{u}+(1-\omega) s_{e} \hat{e}_{t}
$$

\footnotetext{
${ }^{11}$ The final two terms in brackets are irrelevant to comovement because one is predetermined and the other exogenous. Also note that the term $s_{e}-\bar{e} b \bar{\gamma}^{-1}$ is assumed to be positive to ensure marginal utility of consumption is positive in steady state.
} 
It depends on the weighted sum of the individual consumption of the employed and unemployed, and also the employment rate. Changes in participation generate a composition effect on aggregate consumption. The magnitude of this effect depends on $\omega$, the consumption share of the unemployed. In the case of equal consumption of employed and unemployed, $\omega=1$, there is no employment effect on aggregate consumption. In the case where most fluctuations in total hours are determined by the intensive margin, $\hat{e}_{t} \approx 0$, as in standard real-business-cycle theory, there is no composition effect, and aggregate consumption would mimic individual consumption. In this case the assumed normality of preferences would induce negative co-movement between consumption and hours.

Labor force participation is determined by

$$
\phi_{e} \hat{e}_{t}=\hat{W}_{t}+\left[1-\frac{1}{\psi} \frac{(1-\omega)}{1+\left(\bar{e}^{-1}-1\right) \omega}\right] \hat{\lambda}_{t} .
$$

where $\phi_{e}$ determines the Frisch elasticity of participation and it is related to the marginal cost of participating in the labor market and the aggregate wage bill as a fraction of total consumption, $\psi=\bar{W} \bar{N} / \bar{C}$. The ratio $\phi_{e} / \phi_{N}$ affects the relative importance of extensive and intensive margins. The lower the ratio, the stronger the co-movement between consumption and hours.

\section{Calibration}

The model is calibrated to U.S. data. The time period is one quarter. The discount factor, the capital share, and the depreciation rate of capital are determined as $\beta=0.99, \alpha=0.3$ and $\delta=0.025$. Following Jaimovich and Rebelo (2008), the elasticity of capacity utilization is $\epsilon_{\delta}=0.15$. These parameters are fairly common in the real-business-cycle literature.

The labor supply dynamics of the model are affected by the steady-state fraction of household members participating in the labor market, $\bar{e}$; the marginal cost of participat-

ing, $\Phi_{e}(\bar{e})$; the consumption of non-participating households as a fraction of participating households, $\omega$; and the inverse of the Frisch elasticities of hours, $\phi_{N}$, and employment, $\phi_{e}$. We set $\bar{e}=0.68$, roughly in line with the labor market participation rate in the U.S., and $\phi_{N}=1$ consistent with Kimball and Shapiro (2008) and broadly in line with the macro 
literature. ${ }^{12} 13$ The remaining parameters are less standard, requiring further discussion.

Consumption share of non-participants. We choose a baseline specification in which $\omega=0.8$, implying that members of a household that do not participate in the labor market consume 20 percent less than employed members. The number is motivated as follows. We use Consumer Expenditure Survey data on U.S. household expenditures for 1980-2003 to study consumption patterns across households with different levels of labor supply. ${ }^{14}$ Looking at data for married couples with a minimum of 260 hours worked per year the sample is divided into two groups: households that work less than 2600 hours in a year (which corresponds to the 25th percentile) and households working more than this. Households that work more than the threshold are found to consume 19.2 percent more than those below the threshold. ${ }^{15}$ These numbers likely understate the consumption gap between employed and unemployed as our calculations assume households working below the threshold still work a nontrivial number of hours (in contrast to model assumptions). ${ }^{16}$ Of course, the documented drop in consumption might capture the existence of borrowing constraints that are not included in our model. Additional evidence is provided by Aguiar and Hurst (2005) which, using the Continuing Survey of Food Intake of Individuals (CSFII), demonstrate that food consumption falls by roughly 19 percent when individuals transition from employment to unemployment.

The calibration of $\omega$ is below what is suggested in Hall (2009), which assumes consumption of the unemployed to be 15 percent below consumption of employed. Hall's value is primarily based on evidence found in Browning and Crossley (2001), which studies declines in total consumption during periods of unemployment using Canadian data. It considers

\footnotetext{
${ }^{12}$ In particular, the calibrated steady-state corresponds to the average U.S. participation rate computed as the ratio between total civilian employment from household data and the civilian non-institutional population between age 16 age 64 . The years considered are 1948Q1-2008Q1.

${ }^{13}$ Pistaferri (2003), often cited in the macro literature, estimates a Frish elasticity of 0.7 , but focuses only on males.

${ }^{14}$ We thank Gianluca Violante for suggesting the data set and providing the data. The data used here are from Heathcote, Storesletten, and Violante (2008). A detailed description of the dataset can be found in Krueger and Perri (2006).

${ }^{15}$ In detail, we regress consumption on the hours dummy, controlling for age, eductation, race, region, unrban/rural and year. We find a strongly significant coefficient. For consumption, we use the variable consumption nondurable plus. This includes nondurable consumption and imputed services from durable goods such as housing. Details on how this variable is constructed can be found in Krueger and Perri (2006).

${ }^{16}$ The first group of households (working more than 2600 hours) works on average twice as many hours than the second group. Still, the average number of hours worked in the second group is 2000, roughly corresponding to the case in which a member of the couple has a full time job and the other is at home.
} 
only unemployed agents; not non-participants. In Hall's calibration, $\bar{e}$ is set equal to 0.95, consistent with steady-state unemployment. Coupled with $\omega=0.85$ it is roughly the same as our calibration which sets $\omega=0.8$ and $\bar{e}=0.68$. For example, the contribution of changes in employment to changes in aggregate consumption is roughly the same under the two alternative calibrations.

Perfect insurance. Agents are assumed to have perfect insurance. This assumption greatly simplifies the analysis but implies that the observed relation between consumption and hours worked comes from non-separable preferences and not from imperfect insurance. There is much evidence that temporary income shocks are well insured, while permanent shocks are only partially insured — see Attanasio and Davis (1996), Blundell, Pistaferri, and Preston (2008) and Heathcote, Storesletten, and Violante (2008). As discussed by the latter, uninsurable income shocks tend to induce negative correlation between consumption and hours because income effects reduce labor supply - this holds under our preference specification with $\sigma>1$. Furthermore, in their consumption data, taken from the Consumer Expenditure Survey, there is a positive correlation between hours and consumption in the cross section after controlling for income dispersion arising from partially insurable permanent income shocks. Hence, non-separability can explain the positive correlation between hours worked and consumption also when permanent differences in income are present. And the mechanisms delineated in this paper would still be operative even if consumption differentials are in part a result of incomplete markets. A similar argument can be made with respect to differences in wealth.

Marginal cost of participating in the labor market. We calibrate the value for the marginal disutility of working, defined as

$$
\zeta=\bar{\lambda}^{-1} \frac{\Phi_{e}(\bar{e}) \bar{e}}{\psi \bar{C}}=\bar{\lambda}^{-1} \frac{\Phi_{e}(\bar{e}) \bar{e}}{\bar{W} \bar{N}} .
$$

Recall the parameter $\psi$ denotes total wage compensation as a fraction of total consumption. It is set equal to 0.9, roughly in line with empirical evidence - see, for example, Basu and Kimball (2000). The marginal disutility of working is calibrated to $\zeta=0.57$, which implies that the value of not working for any household member is about 43 percent of the flow 
value of employment. To see this, recall in steady state optimality implies

$$
\begin{aligned}
{\left[\frac{\left(\bar{C}^{u}\right)^{1-\sigma} \nu(0)}{1-\sigma}-\frac{\left(\bar{C}^{e}\right)^{1-\sigma} \nu(\bar{n})}{1-\sigma}\right] \bar{\lambda}^{-1}+\bar{C}^{e}-\bar{C}^{u} } & =\bar{W} \bar{n}-\bar{\lambda}^{-1} \Phi_{e}(\bar{e}) \\
& =\bar{W} \bar{n}(1-\zeta) \\
& =0.43 \bar{W} \bar{n} .
\end{aligned}
$$

The left hand side of this expression represents the value in consumption units of shifting a household member from employment to unemployment. It gives the value of leisure. To put this number in perspective, a value of $\zeta$ closer to 0.05 would correspond to the calibration of Hagedorn and Manovskii (2008). Our calibration is closer to Hall (2006) and Shimer (2005), which in our notation implicitly propose values for $\zeta$ of 0.57 and 0.6 .

As a further consistency check, our benchmark calibration implies a cross-elasticity of consumption of the employed with respect to the wage of 0.45 , which is obtained from combining (21) and (22), to give

$$
\begin{aligned}
\hat{C}_{t}^{e}= & \frac{(\sigma-1)}{\sigma} \frac{\psi}{s_{e}} \hat{W}_{t}-\left[\frac{s_{e}-b \bar{\gamma}^{-1} \bar{e}}{s_{e}}-\frac{(\sigma-1)}{\sigma} \frac{\psi}{s_{e}}\right] \sigma^{-1} \hat{\lambda}_{t}+ \\
& +\frac{b \bar{e} \bar{\gamma}^{-1}}{s_{e}}\left(-\hat{\gamma}_{t}+\hat{C}_{t-1}\right) .
\end{aligned}
$$

The cross-elasticity of consumption of the employed, is above what is suggested in Hall (2009), which assumes a cross-elasticity of 0.3. The cross-elasticity is pinned down by the steady state of the model.

Given the chosen values for $\omega$ and $\zeta$, the inverse intertemporal elasticity of substitution is inferred from the steady-state restriction

$$
\sigma=\left[1-\frac{1}{\psi} \frac{(1-\zeta)(1-\omega)}{1+\left(\bar{e}^{-1}-1\right) \omega}\right]^{-1}
$$

This implies $\sigma=1.56$. The value is broadly consistent with the empirical literature on intertemporal substitution in consumption, and in the mid-range between the values of 1 and 3 often used in the macroeconomic literature. ${ }^{17}$ To gauge robustness, consider calibrating $\sigma=2$, as commonly done in macroeconomic studies. From (24) this implies $\zeta=0.3$. This calibration delivers a slightly higher co-movement between aggregate consumption and total hours than our baseline. The stronger co-movement results from a larger employment

\footnotetext{
${ }^{17}$ See Hall (2009) for a discussion on this literature.
} 
response (due to the lower marginal cost of participating) at the expense of the hours response. However, we constrain the relative response of the intensive and extensive margins to be broadly consistent with US data.

Frisch elasticity of employment (extensive margin). In the benchmark calibration, we assume that the ratio of the inverse Frisch elasticity of the supply of hours is one fourth the inverse Frisch elasticity of employment, $\phi_{e} / \phi_{N}=1 / 4$. This choice approximates the observed relative volatility of employment to total hours. ${ }^{18}$ To calibrate this parameter we use measures of hours per worker, employment and total hours that come from payroll data from the establishment survey, covering the non-farm private business sector. ${ }^{19}$ The payroll data does not permit decomposing employment variations into changes in unemployment and labor force participation - the former margin not considered here given the absence of involuntary unemployment. The relative standard deviation of employment and total hours is 0.84 , in line with what is obtained from simulating the model under the benchmark calibration (see section 6 and, in particular, Table II).

The model predicts individual hours and employment to be perfectly correlated, implying a relative standard deviation between individual hours and employment of about $20 \%$. However, in the data, individual hours display a weaker correlation with total hours than employment. While the correlation of total hours with employment is 0.97 , the correlation between individual hours and total hours is 0.68. Moreover, the correlation between individual hours and employment is 0.48 . As a result the relative volatility of individual hours to employment implied by the model is lower than in the data. This weak correlation is absent in the model because only one particular class of disturbance is adopted which have the property of inducing perfect correlation between individual hours and employment. Permitting exogenous fluctuations in the marginal cost of participation would induce a negative correlation between individual hours and employment, reconciling the model with the data.

The relative volatility of total hours and output implied by the calibrated model is consistent with observed data. The measure of total hours that we consider is the adjusted measure of total hours per capita Francis and Ramey (2008).

Implied composition effects on aggregate consumption. The key determinant of comovement in the model is the composition effect on aggregate consumption generated

\footnotetext{
${ }^{18}$ Similar calibration is used in Dotsey and King (2006). See also Table II in Section 6.4.

${ }^{19}$ The data range from 1948Q1-2008Q1.
} 
by variations in employment. Given the calibration for the consumption share of nonparticipants, the participation rate and the relative importance of the extensive margin, we can provide a back-of-the-envelope quantitative evaluation of the magnitude of the composition effect. The volatility of consumption expressed as the relative standard deviation with respect to output for post-war data is roughly $50 \%$. The relative standard deviation of total hours to output is $90 \% .{ }^{20}$ The relative volatility of employment to output is $0.9 \times 0.84=76 \%$. The composition effect is then

$$
(1-\omega) s_{e} \frac{\sigma_{e}}{\sigma_{y}}=\frac{(1-\omega) \bar{e}}{\bar{e}+(1-\bar{e}) \omega} \frac{\sigma_{e}}{\sigma_{y}}=0.11
$$

which corresponds to roughly one fifth of consumption volatility. This implies a nonnegligible role of composition effects.

Real frictions. We set a low level of investment adjustment costs, with $\phi^{\prime \prime}=0.5$. Investment adjustment costs only play a role for co-movement in the case of news shocks, as will be discussed below. This particular value is chosen as it is the greatest value of $\phi^{\prime \prime}$ such that hours increase after a stationary productivity shock. Larger values imply stronger co-movement but hours fall in response to technology shocks. The sensitivity of our results to changes in this parameter is discussed in the next section. For habit formation, we choose $b=0.5$, slightly above microeconomic evidence but lower than macro-estimates. ${ }^{21}$ It satisfies the steady-state restriction $\omega s_{e}-b \bar{\gamma}^{-1} \bar{e}>0$, which ensures consumption of the unemployed is higher than their habit component, $b C \cdot{ }^{22}$ The properties of exogenous disturbances are discussed as they arise.

The benchmark calibration is summarized in Table I.

Table I. Benchmark Calibration.

\begin{tabular}{lllllllllllll}
\hline \hline$\omega$ & $\beta$ & $\phi_{N}$ & $1-\zeta$ & $\phi_{e}$ & $\epsilon_{\delta}$ & $\phi^{\prime \prime}(1)$ & $\bar{e}$ & $b$ & $\alpha$ & $\delta$ & $\bar{\gamma}$ & $\sigma$ \\
\hline 0.8 & 0.99 & 1 & 0.43 & $1 / 4$ & 0.15 & 0.5 & 0.68 & 0.5 & 0.3 & 0.025 & 1.0053 & 1.56 \\
\hline
\end{tabular}

\footnotetext{
${ }^{20}$ See Table II below.

${ }^{21}$ (Ravina 2005) estimates an external habit coefficient of 0.29 and an internal habit coefficient of 0.5.

${ }^{22}$ As in other log-linearized models including habit formation, it is assumed that shocks are 'small' enough such that this does not occur too often in simulations.
} 


\section{Macroeconomic co-movement}

This section describes the response of the economy to alternative demand shocks that have been considered in the literature. In principle, all models can generate positive co-movement without relying on total factor productivity changes. Consistently with the empirical literature on various kinds of demand shocks, the existence and strength of co-movement depends on parameter values. The following is not intended to adduce evidence on the relative importance of any specific shock in business-cycle dynamics. This would require estimating and investigating a more complex model of the economy. However, results do suggest that nonseparable preferences and heterogeneity are potential resolutions to co-movement problems arising in neoclassical theory.

\subsection{Investment-specific technology shocks}

Shocks to investment demand have received considerable attention in the business-cycle literature. They are here emphasized on three grounds. First, as motivated by Greenwood, Hercowitz, and Huffman (1988), investment-specific technology shocks can be interpreted as shifts in the marginal efficiency of investment; or, alternatively, "news" about future returns to investment, which Keynes (1936) considered a major determinant of business cycles. However, in standard real-business-cycle models, investment-specific shocks coupled with endogenous capacity utilization, induce substitution of resources towards new investment goods, and toward higher usage of existing capital, increasing investment at the expense of consumption. Greenwood, Hercowitz, and Huffman (1988) resolve this difficulty by assuming preferences which eliminate the wealth effect on labor supply. The approach of this paper does not take a stand on whether wealth effects are large or small. Instead, it proposes preferences which are calibrated to observable characteristics of data.

Second, Eusepi and Preston (2008) show that a real-business-cycle model augmented with adaptive learning produces expectation-driven business cycles, induced by shifts in beliefs about future returns to capital. Changes in expectations, endogenous to neutral technology shocks, produce fluctuations in the demand for investment which have similar substitution effects as in the case of exogenous investment-specific technology shocks.

Third, evidence supports investment-specific technology shocks being a major source of business-cycle variation. Both the empirical vector autoregression and structural DSGE 
model literatures attest to this — see Fisher (2006), Justiniano and Primiceri (2008) and Justiniano, Primiceri, and Tambalotti (2008). Investment-specific shocks have been interpreted as reduced-form measures of efficiency in financial markets and as finance premium shocks in models of the financial accelerator. Despite these research efforts, it has proven difficult to obtain positive co-movement between consumption, hours and investment conditional on this type of shock, even in models that include a variety of nominal and real fictions.

Figure 1 shows the impulse response of consumption, output, investment and total hours to an investment-specific technology shock. The solid line shows the model response under our benchmark calibration which assumes $\omega$, the consumption share of non-participants, to be equal to 0.8 . The dotted line describes the real-business-cycle model where $\omega=1$. We assume the investment-specific technology shock, $\hat{q}_{t}$, to be first-order autoregression with autocorrelation coefficient equal to $0.85 .{ }^{23}$ The qualitative response of the economy under the benchmark calibration is not affected by the choice of this parameter.

Under the real-business-cycle calibration, consumption drops on impact and remains below steady state for approximately ten quarters. In contrast, the non-separable preferences model produces positive co-movement between investment, hours and consumption. Labor productivity increases slightly (because of the higher utilization of existing capital) but by less than aggregate consumption. In fact, the consumption response is twice as large on impact and nearly three times as large at the peak, after five quarters. As shown in Figure 2, this is not true for individual consumption of the employed and unemployed. Consumption of non-participants decreases slightly in accordance with strong substitution effects, while consumption of employed workers increases, but by less than the increase in productivity. ${ }^{24}$ These relative magnitudes are observed because normality of consumption and leisure makes it impossible to have individual consumption and hours co-move unless TFP increases more than proportionally. Figure 2 also shows both employment and hours increase and that the extensive margin accounts for a large part of total hours variation.

As a final note, neither habit formation nor investment adjustment costs are required

\footnotetext{
${ }^{23}$ To put this number into perspective, in estimated models values range from 0.72 in Justiniano and Primiceri (2008) to 0.87 in Justiniano, Primiceri, and Tambalotti (2008). In calibrated models, Greenwood, Hercowitz, and Huffman (1988) use $\rho_{I}=0.84$ and Greenwood, Hercowitz, and Krusell (2000) use $\rho_{I}=0.89$ in terms of quarterly frequency. In contrast, Jaimovich and Rebelo (2008) assume a unit root.

${ }^{24}$ The small rise in employed consumption is a consequence of investment adjustment costs.
} 

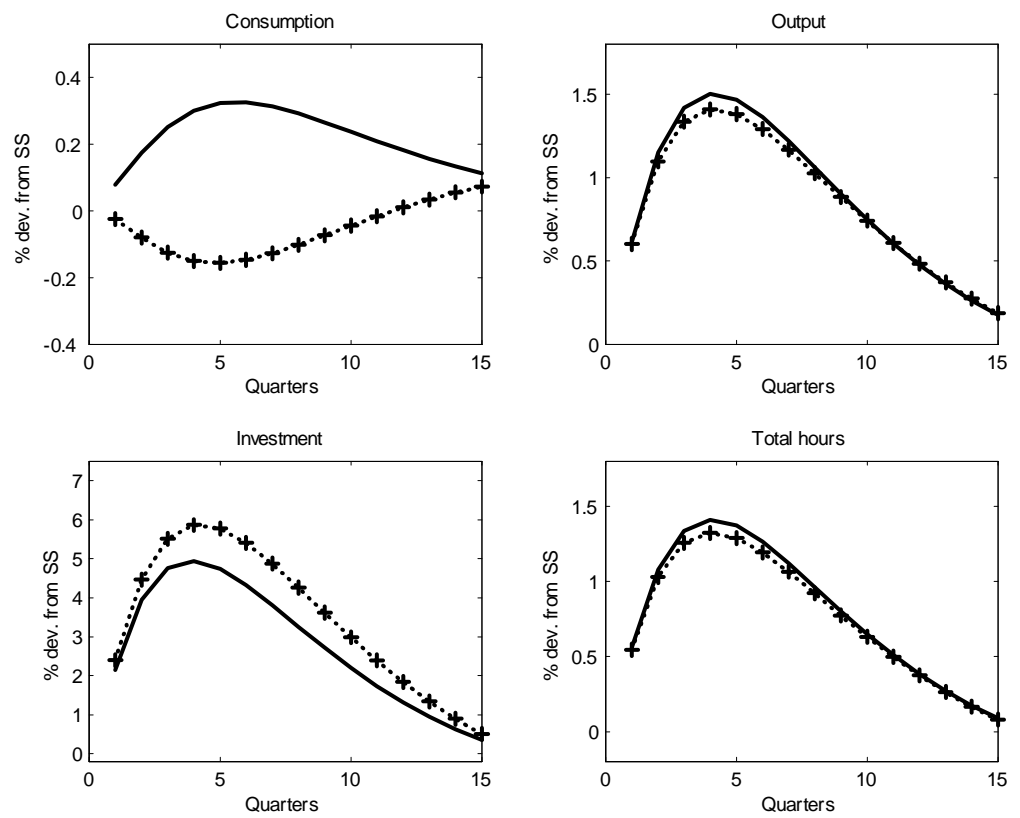

Figure 1: Impulse response to an investment-specific shock. The solid line represents our benchmark economy with $\omega=0.8$. The dotted line indicates the model's response assuming $\omega=1$.
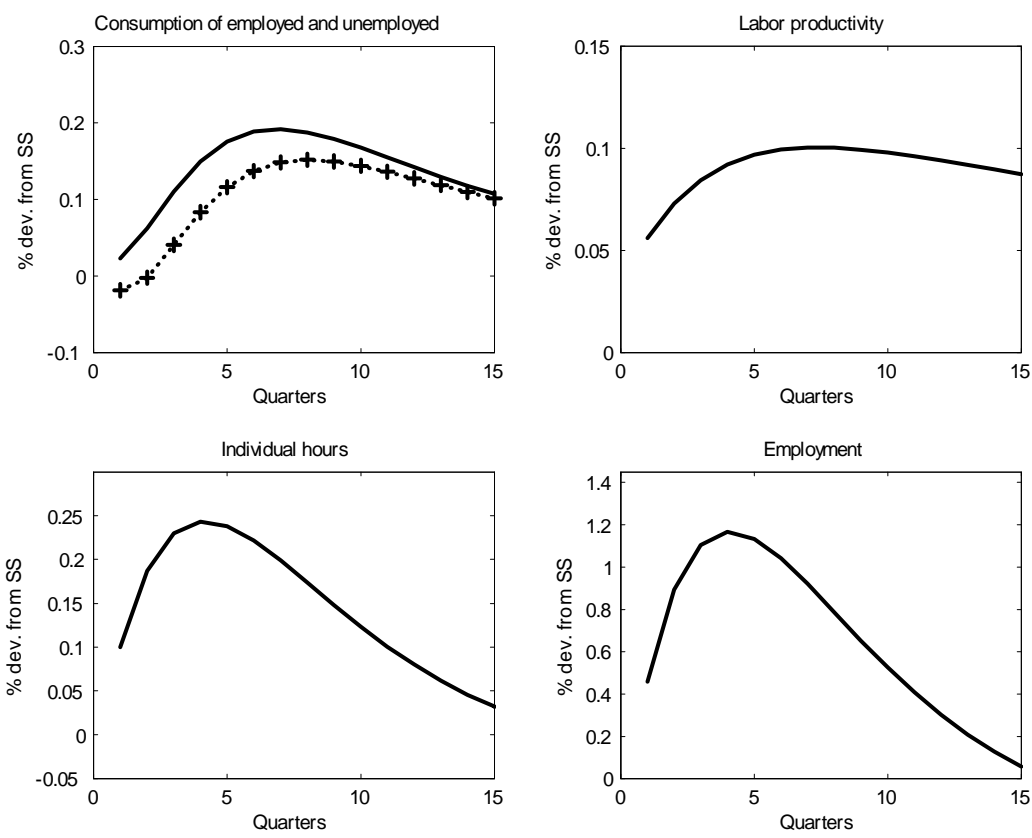

Figure 2: Impulse response to an investment-specific shock. The Figure refers to the benchmark model with $\omega=0.8$. The solid line indicates the response of employed and the dotted line represents the consumption response of non-participants. 
for co-movement, although habit formation plays a role in magnifying the consumption response.

\subsection{News shocks}

In a series of papers, Beaudry and Portier (2004, 2006, 2007) have sparked renewed interest in the notion of news-driven business cycles. We define a "news shock" as new information about future TFP productivity modelled according to

$$
\hat{A}_{t}=\rho_{a} \hat{A}_{t-1}+\epsilon_{t-p}+\xi_{t}
$$

where $\hat{A}_{t}$ is a stationary TFP process, and $\epsilon_{t}$ and $\xi_{t}$ are i.i.d. disturbances. ${ }^{25}$ The shock $\epsilon_{t}$ affects TFP $p$-periods later. The shock $\epsilon_{t}$ does not affect current TFP but provides information about its future evolution.

The role of news shocks in the business cycle is still controversial. Schmitt-Grohe and Uribe (2008) find that news shocks play a key role in business-cycle fluctuations in an estimated real-business-cycle model. Evidence on news shocks using structural vector autoregressions is mixed. Sims (2009) proposes an identification which results in news shocks leading to a decrease in hours and investment, and a small increase in consumption. Beaudry and Lucke (2009), using a different identification scheme and a different set of variables, show that an identified news shock leads to a sharp increase in hours and stock prices, as suggested in Beaudry and Portier (2006).

In a real-business-cycle model this news shock would increase consumption but reduce hours and investment because of the positive wealth effect. In contrast, our benchmark model without investment adjustment costs would produce co-movement, but of the wrong kind: it would imply a drop in consumption as well! This is because the wealth effect would induce lower participation and thus lower aggregate consumption, while individual consumption of the employed and unemployed increase. To generate a positive response in hours and investment, agents need an incentive to invest today, to capture benefits of higher TFP tomorrow. Following Jaimovich and Rebelo (2008), adjustment costs to investment provide a reduced-form representation of the economic mechanisms that would induce investment in the current period. With high enough adjustment costs, so that the substitution effect dominates the wealth effect, hours and investment rise in response to a news shock.

\footnotetext{
${ }^{25}$ See, for example, Christiano, Ilut, Motto, and Rostagno (2007) and Schmitt-Grohe and Uribe (2008).
} 
Worth underscoring is that news shocks about productivity can be thought of as a special case of a TFP shock which is more persistent than a random walk. As shown in Campbell (1994) for the standard RBC model, the long-term effect of the shock dominates the initial effect so that income effects drive consumption and hours in opposite direction. Hence, TPF shocks need to satisfy restrictions on their persistence to deliver comovement. Such restrictions depend on the specifics of the model; in particular its ability to generate strong substitution effects via adjustment costs to investment, endogenous capacity utilization and aggregate labor supply elasticity.

A more appealing approach to modeling news shocks about technology is offered in Comin, Gertler, and Santacreu (2009). ${ }^{26}$ Agents receive news about future production possibilities, but to adopt them, firms must start investing when the news arrives. Endogenous technology adoption produces strong substitution effects, generating an increase in hours and investment. A similar mechanism is present in Li and Mehkari (2009), which has endogenous firm entry and entry costs that depend positively on the number of existing firms. $^{27}$

The mechanisms operating in Comin, Gertler, and Santacreu (2009) reveal a more fundamental issue in the literature on news shocks. Because of strong substitution effects arising from technology adoption, the co-movement problem is inverted in their model: consumption falls on impact (or increases weakly if the model is augmented with endogenous entry) and hours and investment rise in response to a positive news shock. ${ }^{28}$ As mentioned above, this property is common to Eusepi and Preston (2008) which seeks to endogenize how news about future TFP affects current resource use. Beliefs about future returns to capital are revised endogenously to TFP shocks, leading to dynamics that are qualitatively like investment-specific technology shocks. The model proposed here helps reconcile the high substitution effects required to generate an economic expansion after a news shock with the observed co-movement between consumption, hours and investment. It does so without the need to assume a sufficiently high degree of aggregate increasing returns to scale to allow

\footnotetext{
${ }^{26}$ They also get desired movement in asset prices, which the current model fails to get. For a discussion see Jaimovich and Rebelo (2008).

${ }^{27}$ Firms have an incentive to enter the market before the productivity shock is realized to limit the cost of entry. At the same time, endogenous entry, coupled with very inelastic capacity utilization cost, produces an immediate increase in TFP, allowing investment hours and consumption to co-move.

${ }^{28}$ Consumption falls after a TFP shock because of strong substitution effects.
} 

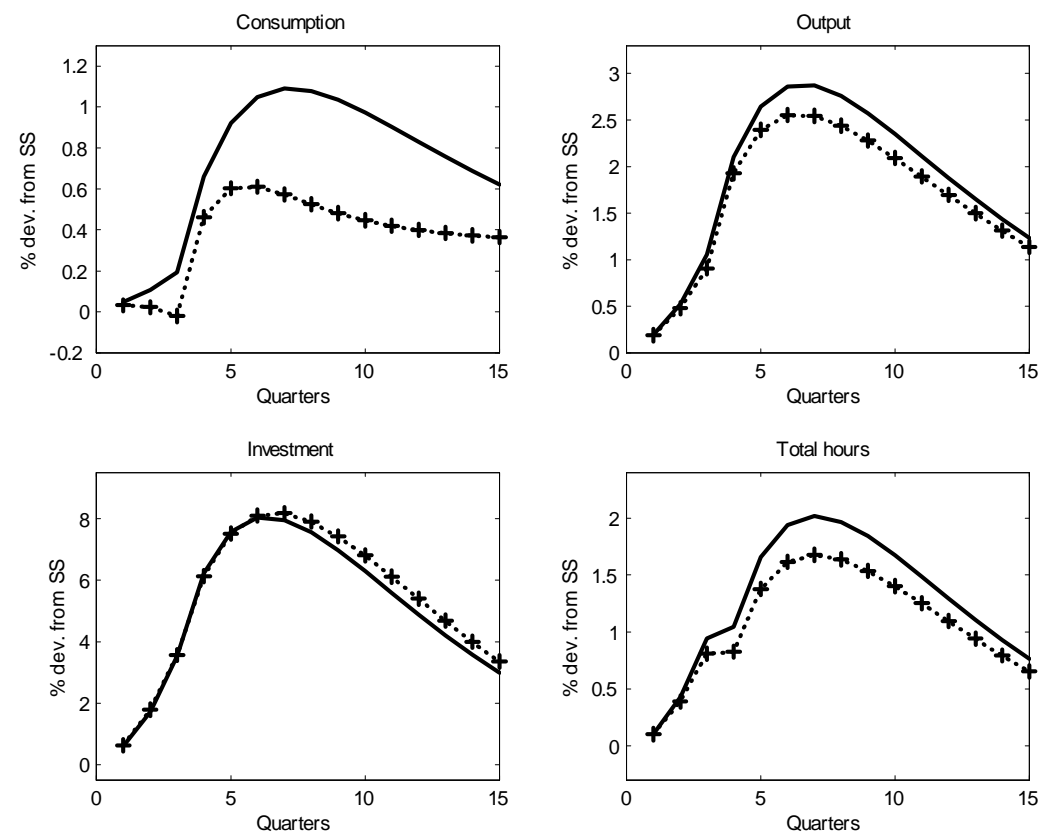

Figure 3: Impulse response to a news shock. The solid line represents our benchmark economy with $\omega=0.8$. The dotted line indicates the model's response assuming $\omega=1$.

consumption to move in the right direction.

Figures 3 and 4 illustrate the response of the economy to the news of a positive productivity shock in the fourth quarter $(p=3)$, where the horizon is chosen for comparison with the estimate of Schmitt-Grohe and Uribe (2008). The impulse response corresponds to the benchmark calibration. Additionally, we set the autocorrelation coefficient $\rho_{a}$ to 0.9 , as in Schmitt-Grohe and Uribe (2008) and Christiano, Ilut, Motto, and Rostagno (2007). In the real-business-cycle model, consumption drops below its steady-state value after the initial increase, because of substitution effects. In the non-separable preferences model, aggregate consumption increases gradually before the shock is realized, as employment responds positively to the news shock. The magnitude of the response and the existence of co-movement of course depends on chosen parameters. Under our benchmark calibration, positive comovement is obtained for values of the investment adjustment costs parameter as low as 0.3 - for lower values hours and investment drop as substitution effects are too weak.

Note that the longer is the horizon over which news is relevant, the weaker will be comovement because substitution effects induced by investment adjustment costs diminish. 

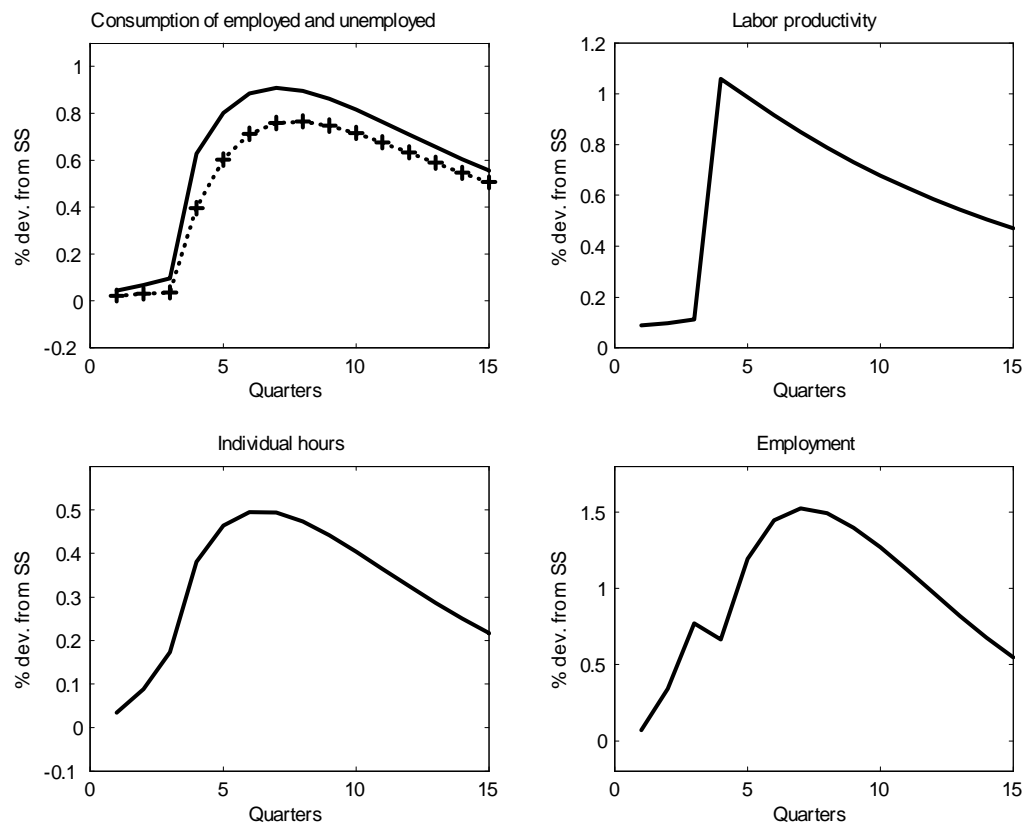

Figure 4: Impulse response to a news shock. The Figure refers to the benchmark model with $\omega=0.8$. The solid line indicates the response of employed and the dotted line represents the consumption response of non-participants.

Similarly, the more persistent are technology shocks the weaker will be co-movement, again because substitution effects are more likely to be dominated by income effects. Aggregate consumption on impact rises less than labor productivity, as the initial response of employment is weak, but in subsequent periods it becomes stronger. Finally, the extensive margin is the main determinant of the response in total hours worked.

The news shock co-movement problem has recently received much attention. Beaudry and Portier (2007) discuss conditions to obtain expectations-driven business cycles in neoclassical models. They show that production complementarities can induce positive comovement. Den Haan and Kaltenbrunner (2007) obtain expectations-driven business cycles in a search model with an inefficient steady-state level of investment. Chen and Song (2007) discuss a model where capital is allocated inefficiently among firms and show the possibility of co-movement in response to news shocks. Guo (2009) suggests a model with financial frictions coupled with additional real frictions such as habit formation and investment adjustment costs. Finally, Christiano, Ilut, Motto, and Rostagno (2007) show that monetary policy can lead to a positive response to news shocks, coupled with a stock market boom. 
The approach detailed here is closely related to Jaimovich and Rebelo's (2008) which modifies preferences proposed by Greenwood, Hercowitz, and Huffman (1988), and, in conjunction with variable capacity utilization and investment adjustment costs, generates comovement. Our model advances that analysis by permitting wealth effects on labor supply. Furthermore, it demonstrates that departures from the representative agent construct may prove fruitful in reconciling certain aspects of theory with data. ${ }^{29}$

\subsection{Government spending shocks}

Baxter and King (1993) investigate the implications of variation in unproductive government expenditures for macroeconomic dynamics in a standard real-business-cycle model. Both permanent and transitory changes in government spending lead to a fall in aggregate consumption and a rise in hours work. Depending on model parameters, investment may rise or fall.

These predictions have been the focus of much empirical research. Galí, López-Salido, and Vallés (2007) provides a useful survey of the literature. For our purposes it suffices to note that there is now an extensive literature on the consumption response to government expenditure shocks. And evidence on the sign of this relationship fails to speak with unanimous voice. Examples on either side of this debate are Blanchard and Perotti (2002), which suggests positive co-movement based on an identified vector autoregression; and Ramey and Shapiro (1998) and Ramey (2008) which suggest negative co-movement based on the so-called narrative approach. ${ }^{30}$ Our intention is not to take a strong stand on any particular piece of evidence. Rather, it is to show that the posited framework is in principle consistent with either correlation, while simultaneously being consistent with positive co-movement in response to investment-specific technology shocks and news shocks.

To this end, consider a shock to the resource constraint. The shock can be interpreted as an unproductive government spending shock, where resources are pulled out of the economy. Assume the shock is a first-order autoregression with autocorrelation coefficient $\rho_{g}=0.99$, consistent with Schmitt-Grohe and Uribe (2008) and Justiniano, Primiceri, and Tambalotti

\footnotetext{
${ }^{29}$ See also Chang and Kim (2007).

${ }^{30}$ Concern about the validty of both identification strategies has been raised by Leeper, Walker, and Yang (2008) which argues invertibility problems arise because agents have foresight about many changes in the fiscal environment that the econometrician is not privy to.
} 

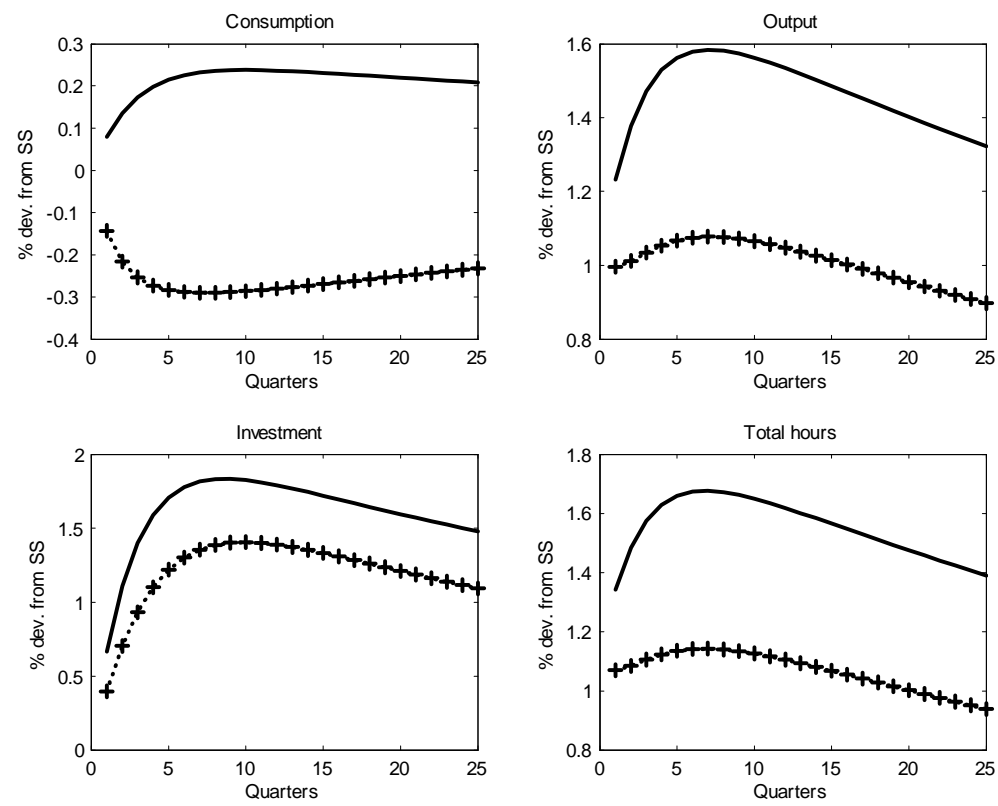

Figure 5: Impulse response to a government spending shock. The solid line represents our benchmark economy with $\omega=0.8$. The dotted line indicates the model's response assuming $\omega=1$.

(2008). Figure 5 shows the benchmark model predicts a small increase in consumption and in investment, while output and hours increase sharply. This shows that the calibrated model can generate a joint positive response in both consumption and investment, as suggested by some vector autoregression evidence. With separable preferences the crowding out of consumption is clear. Figure 6 evidences the role of the extensive margin.

The main difference between government spending shocks and investment-specific technology shocks is that high substitution effects are coupled with a negative wealth effect, as the resources available for investment and consumption shrink. The presence of habit formation is important to obtaining a positive response of consumption to government spending disturbances given the calibration of remaining parameters. For values of the habit parameter, $b$, less than 0.24 , consumption displays a small drop, delivering a response consistent with evidence found in Ramey (2008). Regardless, this parameterization would deliver impulse responses to investment-specific technology shocks and news shocks that are similar to Figures 1 and 2 and Figures 3 and 4 respectively. Lastly, Figure 6 shows that labor productivity (the wage) displays a small drop. The model can produce a positive response 

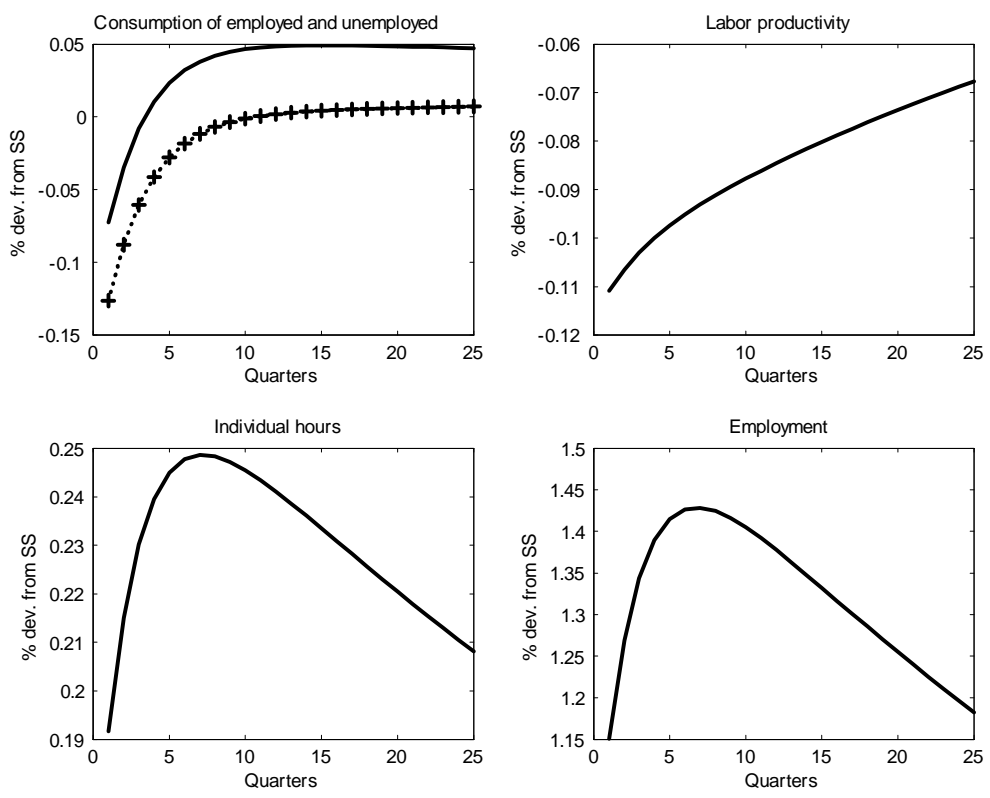

Figure 6: Impulse response to a government spending shock. The Figure refers to the benchmark model with $\omega=0.8$. The solid line indicates the response of employed and the dotted line represents the consumption response of non-participants.

of the real wage with the addition of a countercyclical mark-up, or a mild degree of increasing returns. The minimum required level of increasing returns would not be sufficient to generate a positive response in consumption for low values of habit. ${ }^{31}$

Several recent papers have proposed alternative mechanisms to explain positive comovement in response to unproductive government expenditures shocks. Galí, López-Salido, and Vallés (2007) demonstrate that a model with rule of thumb consumers induces positive co-movement after a government spending shock. However, in their model, the assumption of rule of thumb consumers requires the existence of nominal rigidities to provide co-movement. A model with non-separable preferences and costly labor market participation is not equivalent to assuming rule of thumb consumers. Monacelli and Perotti (2008) use a variant of Greenwood, Hercowitz, and Huffman (1988) preferences proposed by Jaimovich and Rebelo (2008) in conjunction with nominal rigidities to similar effect. However, for consumption to

${ }^{31}$ The model generates an increase in the real wage with with the following production function

$$
Y_{t}=A_{t}\left(K_{t} N_{t}\right)^{0.08} K_{t}^{\alpha}\left(X_{t} N_{t}\right)^{1-\alpha} .
$$


move significantly in response to government shocks requires a parameterization that almost eliminates the wealth effect on labor supply, seemingly inconsistent with evidence in Kimball and Shapiro (2008). As emphasized in earlier discussion, the model presented in this paper obviates the need to take a direct stand on the importance of wealth effects on labor supply. Finally, Ravn, Schmitt-Grohe, and Uribe (2006) explore the role of good-specific habit formation in a real-business-cycle model with monopolistic competition. These so-called deep habits deliver a positive correlation between government spending shocks and consumption.

Closely related to the question of co-movement is the debate about the magnitude of the fiscal multiplier on consumption and output. ${ }^{32}$ The above papers all predict positive impact effects on consumption and also output. However, the magnitude of the output multiplier is small in the case of Ravn, Schmitt-Grohe, and Uribe (2006) and the model proposed by Monacelli and Perotti (2008) generates large effects only when wealth effects on labor supply are small. This paper generates sizeable fiscal multipliers. The impact multiplier of the non-separable preferences model is 1.2; in contrast the separable preference real-business-cycle model has multiplier slightly below one consistent with Baxter and King (1993). Heterogeneity may be quite important for assessing the transmission and effects of policy disturbances.

\subsection{Business-Cycle Statistics}

As a final exercise, Table II shows business-cycle statistics generated by each individual shock along with corresponding moments for U.S. data. ${ }^{33}$ All shocks have unit standard deviation since only relative measures of fit are presented - their scale do not matter. All

\footnotetext{
${ }^{32}$ Interest in the size of the fiscal multiplier has heightened given the current recession. In models incorporating nominal rigidites, Christiano, Eichenbaum, and Rebelo (2009) and Eggertsson (2009) give explicit consideration to the zero lower bound on nominal interest rates and demonstrate that when this constraint is binding fiscal multipliers will be larger than values in normal times, which are approximately unity. The results presented in this paper suggest its not obvious, even under competitive markets and normal times, that the multiplier be near or below unity.

${ }^{33}$ We use US quarterly data from 1948Q1 to 2007Q4. Output is real GDP, consumption is consumption of nondurable goods and services and investment is fixed business investment and consumption durable goods. All series are in real percapita terms using GDP deflator and the Francis and Ramey (2008) measure of population. For total hours we use the measure in Francis and Ramey, with the exception of the statistics involving individual hours and employment for which we use index measures from the total nonfarm business sector. Consequently, we compute the relative volatility and correlation of indiviudual hours and employment with respect to a different measure of total hours: total hours worked in nonfarm business sector. Finally, as a measure of capacity utilization we use the available series for the manufacturing and service sector.
} 
shocks produce positive co-movement among consumption, investment and total hours. ${ }^{34}$ Statistics are comparable to what would be obtained using TFP shocks only as in the standard real-business-cycle model (virtually indistinguishable from the last column in the table and therefore not reported). For the most part, investment-specific technology shocks bear closest resemblance to data moments. Not surprisingly, the model has difficulty capturing properties of labor productivity over the business cycle as current labor productivity can only be increased through increases in capital utilization.

\section{Conclusion}

The paper shows that a model with non-separable preferences and labor market participation can generate positive co-movement between consumption, investment and hours in response to demand shocks. The result is due to two distinct mechanisms. First, individual consumption is affected by the number of hours worked as predicted by theories of home production. Second, variation in participation affects aggregate consumption. The interaction of latter with the consumption heterogeneity induced by the former engenders compositional changes in aggregate consumption that delivers co-movement. The results suggest heterogeneity might be central to explaining some observed characteristics of macroeconomic dynamics.

\footnotetext{
${ }^{34}$ Interestingly, the model successfully produces co-movement in the amount of hours worked in the consumption and investment sector, as opposed to the standard real-business-cycle model which implies a strong negative comovement. This issue is taken up in further detail by Benhabib, Rogerson, and Wright (1991) and DiCecio (2009).
} 
Table II. Business-cycle properties

\begin{tabular}{|c|c|c|c|c|}
\hline & \multicolumn{4}{|c|}{ Model by Shock } \\
\hline & Data & Investment-specific & Government Spending & News \\
\hline & \multicolumn{4}{|c|}{ Panel A: Relative standard deviation } \\
\hline$\sigma_{C} / \sigma_{Y}$ & 0.52 & 0.20 & 0.12 & 0.35 \\
\hline$\sigma_{I} / \sigma_{Y}$ & 2.82 & 3.32 & 1.00 & 2.84 \\
\hline$\sigma_{N} / \sigma_{Y}$ & 0.91 & 0.95 & 1.07 & 0.71 \\
\hline$\sigma_{P r} / \sigma_{Y}$ & 0.50 & 0.05 & 0.07 & 0.34 \\
\hline$\sigma_{P r} / \sigma_{N}$ & 0.55 & 0.05 & 0.07 & 0.48 \\
\hline$\sigma_{U} / \sigma_{Y}$ & 2.30 & 1.13 & 0.85 & 0.80 \\
\hline$\sigma_{e} / \sigma_{N}$ & 0.84 & 0.83 & 0.85 & 0.76 \\
\hline \multirow[t]{2}{*}{$\sigma_{n} / \sigma_{N}$} & 0.27 & 0.17 & 0.15 & 0.24 \\
\hline & \multicolumn{4}{|c|}{ Panel B: Correlation } \\
\hline$\rho_{C, Y}$ & 0.73 & 0.95 & 0.95 & 0.98 \\
\hline$\rho_{I, Y}$ & 0.78 & 1.00 & 0.92 & 0.99 \\
\hline$\rho_{N, Y}$ & 0.87 & 1.00 & 1.00 & 0.98 \\
\hline$\rho_{P r, Y}$ & 0.42 & 0.90 & -0.96 & 0.91 \\
\hline$\rho_{P r, N}$ & -0.08 & 0.89 & -0.97 & 0.81 \\
\hline$\rho_{U, Y}$ & 0.90 & 0.97 & 1.00 & 0.93 \\
\hline$\rho_{n, e}$ & 0.48 & 1.00 & 1.00 & 0.95 \\
\hline \multicolumn{5}{|c|}{ Note: $\operatorname{Pr}$ denotes productivity } \\
\hline
\end{tabular}




\section{Appendix}

\subsection{Model Steady state}

Steady state. Consider the model solution in steady state, expressed in terms of stationary variables. For any non-stationary variable $Z_{t}$ the steady-state value of $Z_{t} / X_{t}$ is denoted $\bar{Z}$.

Deviations from the balanced growth path are denoted $\hat{Z}_{t}=\ln \left(Z_{t} / \bar{Z}\right)$. Similar notation applies to stationary variables which need not be normalized. The real interest rate is defined as

$$
\alpha \frac{\bar{Y}}{\bar{K}}=\frac{\bar{U} \bar{R}^{k}}{\bar{\gamma}}=\frac{\bar{\gamma}^{\sigma} \beta^{-1}-1+\delta}{\bar{\gamma}},
$$

applying the normalization $\bar{U}=1$. In addition we assume $\bar{G}=0$. From the capital accumulation equations we have

$$
\frac{\bar{I}}{\bar{K}}=1-\frac{1-\delta}{\bar{\gamma}}
$$

Next, define

$$
\psi=\frac{\bar{W} \bar{N}}{\bar{C}}=(1-\alpha)\left(\frac{\bar{C}}{\bar{Y}}\right)^{-1}
$$

where we use

$$
\frac{\bar{C}}{\bar{K}}=\frac{\bar{Y}}{\bar{K}}-\frac{\bar{I}}{\bar{K}}
$$

From the labor supply first-order condition we get

$$
\frac{\left(\bar{C}^{e}-b \bar{\gamma}^{-1} \bar{C}\right) \nu^{\prime}(\bar{n})}{\sigma-1}=\nu(\bar{n}) \bar{W}
$$

so that

$$
\frac{\nu^{\prime}(\bar{n}) \bar{n}}{\nu(\bar{n})}=(\sigma-1) \frac{\bar{W} \bar{e} \bar{n}}{\bar{C}} \frac{\bar{C}}{\bar{e}\left(\bar{C}^{e}-b \bar{\gamma}^{-1} \bar{C}\right)}=\frac{(\sigma-1) \psi}{s_{e}-\bar{e} b \bar{\gamma}^{-1}}
$$

where

$$
s_{e}=\bar{C}^{e} \bar{e} / \bar{C}=\frac{\bar{e}}{\bar{e}+(1-\bar{e}) \omega} .
$$

From the first-order condition for participation we have

$$
\frac{\sigma}{\sigma-1}\left(\bar{C}^{e}-\bar{C}^{u}\right)=\bar{W} \bar{n}-\bar{\lambda}^{-1} \Phi_{e}(\bar{e})
$$

Define $\omega=\bar{c}^{u} / \bar{c}^{e}$. Dividing for steady-state consumption and re-arranging we get

$$
\bar{\lambda}^{-1} \frac{\Phi_{e}(\bar{e}) \bar{e}}{\bar{c}}+\frac{\sigma}{\sigma-1}(1-\omega) s_{e}=\psi .
$$


The parameter $\bar{\lambda}^{-1} \frac{\Phi_{e}(\bar{e}) \bar{e}}{\bar{c}}$ measures the marginal cost of participation in terms of consumption units (as a fraction of total consumption). We can express it as a fraction $\zeta$ of wage earnings

$$
\bar{\lambda}^{-1} \frac{\Phi_{e}(\bar{e}) \bar{e}}{\bar{C}}=\frac{\zeta \bar{W} \bar{N}}{\bar{C}}=\zeta \psi .
$$

Substituting in (25) we obtain

$$
\frac{\sigma}{\sigma-1}(1-\omega) s_{e}=(1-\zeta) \psi
$$

This particular expression leads to (24). Finally, the steady-state amount of hours worked can be determined by $\nu(0)$,

$$
\frac{\bar{C}^{e}-b \gamma^{-1} \bar{C}}{\bar{C}^{u}-b \gamma^{-1} \bar{C}}=\frac{s_{e}-b \gamma^{-1} \bar{e}}{\omega s_{e}-b \gamma^{-1} \bar{e}}=\left[\frac{\nu(\bar{n})}{\nu(0)}\right]^{\frac{1}{\sigma}}
$$

where the left hand side is restricted to be positive, or $\omega s_{e}-b \gamma^{-1} \bar{e}>0$. Summing up, the model implies 15 equations in 15 unknowns, given the parameters. We fix $\bar{e}, \omega$ and $\bar{n}$ which determine $\sigma, \nu(\bar{n})$ and $\nu(0)$ consistent with the steady state.

\subsection{Non-separable utility and the normality of consumption and leisure}

Here we assume a stationary environment $(\bar{\gamma}=0)$ for expositional simplicity. Positive growth involves a straightforward adjustment which results in the expression reported in the main text. Consider an individual with preferences

$$
U\left(c_{t}, l_{t}\right)=\frac{\left(c_{t}-b C_{t-1}\right)^{1-\sigma} \nu\left(1-l_{t}\right)}{1-\sigma}
$$

where $n_{t}=1-l_{t}$ and $l_{t}$ denotes time not spend in market activities and where $\nu^{\prime}(n), \nu^{\prime \prime}(n)>$ 0 . The budget constraint is

$$
c_{t}+l_{t} W_{t}=M_{t}
$$

where $M_{t}$ denotes non-labor income. Next, define

$$
\epsilon_{\nu}=\frac{\nu^{\prime \prime}(\bar{n}) \bar{n}}{\nu^{\prime}(\bar{n})}
$$

which defines the curvature of $\nu(\cdot)$ at the steady state. The following Lemma states the first restriction on utility that guarantees concavity. 
Lemma 5 Assume $\epsilon_{\nu}$ satisfies the restriction

$$
\epsilon_{\nu}>\frac{(\sigma-1)^{2}}{\sigma} \frac{\psi}{s_{e}-\bar{e} b \bar{\gamma}^{-1}}
$$

then the utility function (27) is concave.

Proof. Let us consider (27) in terms of consumption and leisure. Then we have

$$
U_{l}=-\frac{(c-b C)^{1-\sigma}}{1-\sigma} \nu^{\prime}(1-l)>0
$$

where $U_{x}$ denoted the marginal utility with respect to the argument $x$, and where, as above, $\nu^{\prime}(\cdot)$ denotes the derivative of $\nu(\cdot)$ with respect to hours worked. Similarly we get

$$
U_{l l}=\frac{(c-b C)^{1-\sigma}}{1-\sigma} \nu^{\prime \prime}(1-l)<0
$$

It is straightforward to show that $U_{c}>0$ and $U_{c c}<0$. Further, concavity requires

$$
U_{c c} \cdot U_{l l}-\left(U_{c l}\right)^{2} \geq 0
$$

Substituting for the partial derivatives gives

$$
\frac{\sigma}{\sigma-1} \nu(n) \nu^{\prime \prime}(n)(c-b C)^{-2 \sigma}-(c-b C)^{-2 \sigma} \nu^{\prime}(n)^{2}
$$

which, simplifying, yields

$$
(c-b C)^{-2 \sigma} \frac{\nu(n)}{n} \nu^{\prime}(n)\left[\frac{\sigma}{\sigma-1} \frac{\nu^{\prime \prime}(n) n}{\nu^{\prime}(n)}-\frac{\nu^{\prime}(n) n}{\nu(n)}\right] .
$$

Evaluating this condition at the model's steady state provides

$$
\frac{\nu^{\prime}(\bar{n}) \bar{n}}{\nu(\bar{n})}=\frac{\bar{W} \bar{n}}{\bar{c}^{e}}(\sigma-1)=\frac{(\sigma-1) \psi}{s_{e}-\bar{e} b},
$$

where for simplicity we assume no growth. Hence, concavity requires

$$
\left[\epsilon_{\nu}-\frac{\psi}{s_{e}-\bar{e} b} s_{e}^{-1} \frac{(\sigma-1)^{2}}{\sigma}\right] \geq 0
$$

The next Lemma states the restrictions required for both consumption and leisure to be normal goods. 
Lemma 6 Consumption and leisure are normal goods if and only if

$$
\epsilon_{\nu}>\frac{(\sigma-1) \psi}{s_{e}-\bar{e} b} .
$$

Violation of the above condition implies that consumption is an inferior good.

Proof. Consider the first-order conditions of the static utility maximization in (27) and (28). Total differentiation of the individual first-order conditions and budget constraint gives

$$
\begin{aligned}
\left(W U_{c c}-U_{c l}\right) \frac{\partial c}{\partial M}+\left(W U_{C l}-U_{l l}\right) \frac{\partial l}{\partial M} & =0 \\
\frac{\partial c}{\partial M}+W \frac{\partial l}{\partial M} & =1
\end{aligned}
$$

where $W$ is kept constant and $M$ denotes non-wage income. We have

$$
\begin{aligned}
\frac{\partial c}{\partial M} & =\left[1-W \frac{U_{c l}-W U_{c c}}{U_{l l}-W U_{c l}}\right]^{-1} \\
& =\left[\left(1-\frac{U_{l}}{U_{c}} \frac{U_{c l}}{\frac{U_{l}}{U_{l l}}-\frac{U_{c c}}{U_{c}}} \frac{U_{c l}}{U_{c}}\right)^{-1}\right] .
\end{aligned}
$$

Substituting for the chosen utility and using the steady-state restrictions described above provides

$$
\frac{\partial c}{\partial M}=\left[1+\frac{\psi}{s_{e}-\bar{e} b}\left(\epsilon_{\nu}-\frac{(\sigma-1) \psi}{s_{e}-\bar{e} b}\right)^{-1}\right]^{-1}
$$

which states that consumption is an inferior good if and only if

$$
-\frac{\psi}{s_{e}-\bar{e} b}<\epsilon_{\nu}-\frac{(\sigma-1) \psi}{s_{e}-\bar{e} b}<0 .
$$

Next, the condition to have both consumption an leisure normal good is

$$
\frac{U_{c l} / U_{l}-U_{c c} / U_{c}}{U_{l l} U_{l}-U_{c l} / U_{c}}<0 .
$$

Substituting for our chosen functional forms we get

$$
\frac{n}{c-b C} \frac{1}{-\epsilon_{\nu}+\frac{(\sigma-1) \psi}{s_{e}-\bar{e} b}}<0
$$

if and only if

$$
\epsilon_{\nu}>\frac{(\sigma-1) \psi}{s_{e}-\bar{e} b} .
$$




\subsection{The log-linearized model I: individual labor supply and nor- mality}

Re-expressing (9) in terms of stationary variables and log-linearizing gives

$$
\frac{(\sigma-1)}{s_{e}-\bar{e} b \bar{\gamma}^{-1}}\left[-s_{e} \hat{C}_{t}^{e}-b \bar{\gamma}^{-1} \bar{e}\left(\hat{\gamma}_{t}-\hat{C}_{t-1}\right)\right]+\epsilon_{\nu} \hat{n}_{t}=\hat{\lambda}_{t}+\hat{W}_{t}
$$

Combining with

$$
\frac{1}{s_{e}-b \bar{\gamma}^{-1} \bar{e}}\left[-s_{e} \hat{C}_{t}^{e}-b \bar{e} \bar{\gamma}^{-1}\left(\hat{\gamma}_{t}-\hat{C}_{t-1}\right)+\frac{(\sigma-1)}{\sigma} \psi \hat{n}_{t}\right]=\sigma^{-1} \hat{\lambda}_{t},
$$

obtained by log-linearization of (4) in stationary terms we get the Frisch individual labor supply

$$
\phi_{N} \hat{n}_{t}=\hat{W}_{t}+\sigma^{-1} \hat{\lambda}_{t}
$$

where the inverse of the Frisch elasticity is defined as

$$
\phi_{N}=\epsilon_{\nu}-\frac{(\sigma-1)^{2}}{\sigma} \frac{\psi}{s_{e}-\bar{e} b \bar{\gamma}^{-1}}
$$

As shown in Lemma 1, concavity of the utility function requires $\phi_{N}>0$. Notice here the term $\bar{\gamma}$ appears as we assume positive growth. We can also express the condition for normality of consumption and leisure in terms of $\phi_{N}$. The implied restrictions on the labor supply are summarized in proposition 4 .

\subsection{The log-linearized model II}

Households. Substituting in (32) for the steady state value of $\sigma$ and for the definition of $s_{e}$ we obtain

$$
\phi_{N} \hat{n}_{t}=\hat{W}_{t}+\left[1-\frac{1}{\psi} \frac{(1-\zeta)(1-\omega)}{1+\left(\bar{e}^{-1}-1\right) \omega}\right] \hat{\lambda}_{t}
$$

For the marginal utility of the unemployed we obtain

$$
\frac{1}{\omega s_{e}-b \bar{\gamma}^{-1} \bar{e}}\left[-\omega s_{e} \hat{C}_{t}^{u}-b \bar{e} \bar{\gamma}^{-1}\left(\hat{\gamma}_{t}-\hat{C}_{t-1}\right)\right]=\sigma^{-1} \hat{\lambda}_{t}
$$

Employment is determined by (7). Re-expressing in terms of stationary variables and log-linearizing we get

$$
\frac{\sigma}{\sigma-1}\left(\hat{C}_{t}^{e}-\omega \hat{C}_{t}^{u}\right) s^{e}=\psi\left(\hat{W}_{t}+\hat{n}_{t}\right)-\epsilon_{e} \bar{\lambda}^{-1} \frac{\Phi_{e} \bar{e}}{\bar{C}} \hat{e}_{t}+\bar{\lambda}^{-1} \frac{\Phi_{e} \bar{e}}{\bar{C}} \hat{\lambda}_{t}
$$


where

$$
\epsilon_{e}=\frac{\Phi_{e e} \bar{e}}{\Phi_{e}}
$$

Using the assumption that the marginal cost of participating in terms of the consumption good is a fraction of labor earnings,

$$
\bar{\lambda}^{-1} \frac{\Phi_{e} \bar{e}}{\bar{C}}=\zeta \psi
$$

we get

$$
\frac{\sigma}{\sigma-1}\left(\hat{C}_{t}^{e}-\omega \hat{C}_{t}^{u}\right) s^{e}=\psi\left(\hat{W}_{t}+\hat{n}_{t}-\epsilon_{e} \zeta \hat{e}_{t}+\zeta \hat{\lambda}_{t}\right)
$$

Furthermore, Combining (31) and (34) with(36) we obtain the inverse Frisch elasticity of participation $\phi=\epsilon_{e} \zeta$ from

$$
\epsilon_{e} \zeta \hat{e}_{t}=\hat{W}_{t}+\left[\frac{(1-\omega) s_{e}}{\psi(\sigma-1)}+\zeta\right] \hat{\lambda}_{t}
$$

By substituting for the values of $\sigma$ and $s_{e}$ that are consistent with the steady state we get (23).

Log-linearization of equations (10), (11) and (12) in stationary terms yields

$$
\begin{gathered}
\epsilon_{\delta} \hat{U}_{t}=\hat{R}_{t}^{K}+\hat{\lambda}_{t}-\hat{\xi}_{t}, \\
\hat{\xi}_{t}=E_{t}\left[\left(1-\beta \bar{\gamma}^{-\sigma}(1-\delta)\right)\left(\hat{R}_{t+1}^{K}+\hat{\lambda}_{t+1}\right)+\beta \bar{\gamma}^{-\sigma}(1-\delta) \hat{\xi}_{t+1}-\sigma \hat{\gamma}_{t+1}\right],
\end{gathered}
$$

and

$$
\hat{\lambda}_{t}-\hat{\xi}_{t}-\hat{q}_{t}=-\bar{\gamma}^{2} \phi^{\prime \prime}\left(\hat{\gamma}_{t}+\hat{I}_{t}-\hat{I}_{t-1}\right)+\beta \bar{\gamma}^{1-\sigma} \bar{\gamma}^{2} \phi^{\prime \prime} E_{t}\left(\hat{\gamma}_{t+1}+\hat{I}_{t+1}-\hat{I}_{t}\right)
$$

where $\epsilon_{\delta}=\delta^{\prime \prime} \bar{U} / \delta^{\prime}$

The capital accumulation equation (3) and the budget/resource constraint are

$$
\bar{\gamma} \hat{K}_{t+1}=\bar{\gamma} \frac{\bar{I}}{\bar{K}} \hat{I}_{t}-(1-\delta) \hat{\gamma}_{t}+(1-\delta) \hat{K}_{t}-\left(\bar{\gamma}^{\sigma} \beta^{-1}-1+\delta\right) \hat{U}_{t}
$$

and

$$
\frac{\bar{I}}{\bar{Y}}\left(\hat{I}_{t}-\hat{q}_{t}\right)+\frac{\bar{C}}{\bar{Y}} \hat{C}_{t}+\hat{G}_{t}=\hat{Y}_{t}
$$

Finally, total hours are

$$
\hat{N}_{t}=\hat{e}_{t}+\hat{n}_{t}
$$


Firms. Log-linearization of the firm's first-order conditions and production function gives

$$
\hat{W}_{t}=\hat{Y}_{t}-\hat{N}_{t}
$$

where

$$
\hat{Y}_{t}=\hat{A}_{t}-\alpha \hat{\gamma}_{t}+\alpha \hat{U}_{t}+\alpha \hat{K}_{t}+(1-\alpha) \hat{N}_{t}
$$

and

$$
\hat{R}_{t}^{K}=\hat{y}_{t}-\hat{U}_{t}-\hat{K}_{t}+\hat{\gamma}_{t}
$$




\section{References}

Abel, A. B. (1990): "Asset Prices under Habit Formation and Catching up with the Jonses," American Economic Review Papers and Proceedings, 90, 38-42.

Aguiar, M., and E. Hurst (2005): "Consumption versus Expenditure," Journal of Political Economy, 113(5), 919-948.

Attanasio, O., and S. J. Davis (1996): "Relative Wage Movements and the Distribution of Consumption," Journal of Political Economy, 104(6), 1227-62.

Barro, R. J., and R. G. King (1984): "Time-separable Preferences and IntertemporalSubstitution Models of Business Cycles," The Quarterly Journal of Economics, 99(4), 817-39.

Basu, S., and M. Kimball (2000): "Long Run Labor Supply and the Elasticity of Intertemporal Substitution for Consumption," mimeo, University of Michigan.

Baxter, M., and U. J. Jermann (1999): "Household Production and the Excess Sensitivity of Consumption to Current Income," American Economic Review, 89(4), 902-920.

Baxter, M., and R. King (1993): "Fiscal Policy in General Equilibrium," American Economic Review, 30, 73-86.

Beaudry, P., and B. Lucke (2009): "Letting Different Views About Business Cycles Compete," NBER Working Paper 14950.

Beaudry, P., and F. Portier (2004): "Exploring Pigou's Theory of Cycles," Journal of Monetary Economics, 51(6), 1183-1216.

— (2006): "Stock Prices, News, and Economic Fluctuations," American Economic Review, 96(4), 1293-1307.

(2007): "When can changes in expectations cause business cycle fluctuations in neo-classical settings?," Journal of Economic Theory, 135(1), 458-477.

Becker, G. S. (1965): "A Theory of the Allocation of Time," The Economic Journal, $75(299), 493-517$. 
Benhabib, J., R. Rogerson, and R. Wright (1991): "Homework in Macroeconomics: Household Production and Aggregate Fluctuations," Journal of Political Economy, 99(61), 1166-1187.

Bennett, R. L., and R. E. A. Farmer (2000): "Indeterminacy with Non-separable Utility," Journal of Economic Theory, 93(1), 118-143.

BilBiIe, F. (2008): "Nonseparable preferences, fiscal policy puzzles and inferior goods," Journal of Money, Credit and Banking, forthcoming.

Blundell, R., L. Pistaferri, and I. Preston (2008): "Consumption Inequality and Partial Insurance," American Economic Review, 98(5), 1887-1921.

Browning, M., and T. F. Crossley (2001): "Unemployment insurance benefit levels and consumption changes," Journal of Public Economics, 80(1), 1-23.

Campbell, J. Y. (1994): "Inspecting the mechanism: An analytical approach to the stochastic growth model," Journal of Monetary Economics, 33(3), 463-506.

Chang, Y., And S.-B. Kim (2007): "Heterogeneity and Aggregation: Implications for Labor-Market Fluctuations," American Economic Review, 97(5), 1939-1956.

Chen, K., and Z. Song (2007): "Financial Friction, Capital Reallocation and ExpectationDriven Business Cycles," MPRA Paper 3889, University Library of Munich, Germany.

Cho, J.-O., and T. F. Cooley (1994): "Employment and hours over the business cycle," Journal of Economic Dynamics and Control, 18(2), 411 - 432.

Christiano, L., C. Ilut, R. Motto, and M. Rostagno (2007): "Monetary Policy and Stock Market Boom-Bust Cycles," mimeo, Northwestern University.

Christiano, L. J., M. Eichenbaum, and S. Rebelo (2009): "When is the Government Spending Multiplier Large," unpublished, Northwestern University.

Comin, D., M. Gertler, and A. M. Santacreu (2009): "Changes in Growth Potential and Endogenous Technology Diffusion as Sources of Output and Asset Price Fluctuations," mimeo, New York University.

Den Haan, W., and G. Kaltenbrunner (2007): "Anticipated Growth and Business Cycles in Matching Models," CEPR Discussion Papers 6063, C.E.P.R. Discussion Papers. 
DiCecio, R. (2009): "Sticky Wages and Sectoral Labor Comovement," Journal of Economic Dynamics and Control, 33, 538-553.

Dotsey, M., And R. G. King (2006): "Pricing, Production, and Persistence," Journal of the European Economic Association, 4(5), 893-928.

Eggertsson, G. (2009): "Can a Tax Cut Deepen the Recession?," unpublished, Federal Reserve Bank of New York.

Eusepi, S., And B. Preston (2008): "Expectations, Learning and Business Cycle Fluctuations," NBER Working Papers 14181, National Bureau of Economic Research, Inc.

Fisher, J. D. M. (2006): "The Dynamic Effects of Neutral and Investment-Specific Technology Shocks," Journal of Political Economy, 114(3), 413-451.

Francis, N., And V. RAmey (2008): "Measures of Per Capita Hours and their Implications for the Technology-Hours Debate," unpublished, University of California, San Diego.

Galí, J., J. D. LÓPez-SAlido, And J. VAllés (2007): "Understanding the Effects of Government Spending on Consumption," Journal of the European Economic Association, $5(1), 227-270$.

Greenwood, J., Z. Hercowitz, and G. W. Huffman (1988): "Investment, Capacity Utilization and the Real Business Cycle," American Economic Review, 78(3), 402-417.

Greenwood, J., Z. Hercowitz, and P. Krusell (2000): "The role of investmentspecific technological change in the business cycle," European Economic Review, 44(1), $91-115$.

Guo, S. (2009): "News shocks, expectations driven business cycles and financial market frictions," mimeo, Concordia University.

Hagedorn, M., and I. Manovskit (2008): "The Cyclical Behavior of Equilibrium Unemployment and Vacancies Revisited," American Economic Review, 98(4), 1692-1706.

Hall, R. (2006): "Work-Consumption Preferences and Employment Volatility," mimeo, Stanford University.

(2008): "Sources and Mechanisms of Cyclical Fluctuations in the Labor Market," mimeo, Stanford University. 
(2009): "Reconciling Cyclical Movements in the Marginal Value of Time and the Marginal Product of Labor," mimeo, Stanford University.

Hansen, G. (1985): "Indivisible Labor and the Business Cycle," Journal of Monetary Economics, 16, 309-337.

Heathcote, J., K. Storesletten, and G. L. Violante (2008): "The Macroeconomic Implications of Rising Wage Inequality in the United States," mimeo, New York University.

Hintermaier, T. (2003): "On the minimum degree of returns to scale in sunspot models of the business cycle," Journal of Economic Theory, 110(2), 400-409.

Jaimovich, N., and S. Rebelo (2008): "Can News About the Future Drive the Business Cycle?," American Economic Review, forthcoming.

Justiniano, A., And G. E. Primiceri (2008): "The Time-Varying Volatility of Macroeconomic Fluctuations," American Economic Review, 98(3), 604-41.

Justiniano, A., G. E. Primiceri, and A. Tambalotti (2008): "Investment Shocks and Business Cycles," CEPR Discussion Papers 6739, C.E.P.R. Discussion Papers.

Keynes, J. M. (1936): The General Theory of Employment, Interest and Money. Macmillan Cambridge University Press.

Kimball, M. S., And M. D. Shapiro (2008): "Labor Supply: Are the Income and Substitution Effects Both Large or Both Small," NBER Working Paper 14208.

King, R. G., And S. T. Rebelo (1999): "Resuscitating real business cycles," in Handbook of Macroeconomics, ed. by J. B. Taylor, and M. Woodford, vol. 1 of Handbook of Macroeconomics, chap. 14, pp. 927-1007. Elsevier.

Krueger, D., And F. Perri (2006): "Does Income Inequality Lead to Consumption Inequality? Evidence and Theory," Review of Economic Studies, 73(1), 163-193.

Kydland, F. E., and E. C. Prescott (1982): "Time to Build and Aggregate Fluctuations," Econometrica, 50(6), 1345-1370.

Leeper, E., T. B. Walker, And S. S. YAng (2008): "Fiscal Foresight: Analytics and Econometrics," unpublished, Indiana University. 
Li, N., And M. S. Mehkari (2009): "Expectation Drive Firm Dynamics and Business Cycles," unpublished, Ohio State University.

Linnemann, L. (2006): "The Effect of Government Spending on Private Consumption: A Puzzle?," Journal of Money, Credit and Banking, 38(7), 1715-1735.

Monacelli, T., and R. Perotti (2008): "Fiscal Policy, Wealth Effects, and Markups," unpublished, Universita Bocconi.

Ramey, V. (2008): "Identifying Government Spending Shocks: It's All in the Timing," unpublished, University of California, San Diego.

Ravina, E. (2005): "Habit Persistence and Keeping Up with the Joneses:Evidence from Micro Data," NYU Working Paper FIN-05-046, NYU.

Ravn, M., S. Schmitt-Grohe, and M. Uribe (2006): "Deep Habits," Review of Economic Studies, 73, 195-218.

Rogerson, R. (1988): "Indivisible labor, lotteries and equilibrium," Journal of Monetary Economics, 21(1), 3-16.

Schmitt-Grohe, S., And M. Uribe (2008): "What's News in Business Cycles," NBER Working Papers 14215, National Bureau of Economic Research, Inc.

Shimer, R. (2005): "The Cyclical Behavior of Equilibrium Unemployment and Vacancies," American Economic Review, 95(1), 25-49.

- (2009): "Convergence in Macroeconomics: The Labor Wedge," American Economic Journal: Macroeconomics, 1(1), 280-97.

Sims, E. R. (2009): "Expectations Driven Business Cycles: An Empirical Evaluation," mimeo, University of Michigan.

Trabandt, M., and H. Uhlig (2006): "How Far Are We From the Slippery Slope? The Laffer Curve Revisited," CEPR Discussion Papers 5657, C.E.P.R. Discussion Papers. 